\title{
Climatological Mean Circulation at the New England Shelf Break
}

\author{
Weifeng G. Zhang, Glen G. Gawarkiewicz, And Dennis J. McGillicuddy JR. \\ Woods Hole Oceanographic Institution, Woods Hole, Massachusetts \\ JOHN L. WILKIN \\ Institute of Marine and Coastal Sciences, Rutgers, The State University of New Jersey, New Brunswick, New Jersey
}

(Manuscript received 15 October 2010, in final form 19 April 2011)

\begin{abstract}
A two-dimensional cross-shelf model of the New England continental shelf and slope is used to investigate the mean cross-shelf and vertical circulation at the shelf break and their seasonal variation. The model temperature and salinity fields are nudged toward climatology. Annual and seasonal mean wind stresses are applied on the surface in separate equilibrium simulations. The along-shelf pressure gradient force associated with the along-shelf sea level tilt is tuned to match the modeled and observed depth-averaged along-shelf velocity. Steady-state model solutions show strong seasonal variation in along-shelf and cross-shelf velocity, with the strongest along-shelf jet and interior onshore flow in winter, consistent with observations. Alongshelf sea level tilt associated with the tuned along-shelf pressure gradient increases shoreward because of decreasing water depth. The along-shelf sea level tilt varies seasonally with the wind and is the strongest in winter and weakest in summer. A persistent upwelling is generated at the shelf break with a maximum strength of $2 \mathrm{~m} \mathrm{day}^{-1}$ at 50-m depth in winter. The modeled shelfbreak upwelling differs from the traditional view in that most of the upwelled water is from the upper continental slope instead of from the shelf in the form of a detached bottom boundary layer.
\end{abstract}

\section{Introduction}

The Middle Atlantic Bight (MAB) continental shelfbreak region contains a persistent thermohaline front, an along-shelf jet (Fratantoni and Pickart 2003; Gawarkiewicz et al. 2001; Houghton et al. 2009), and high biological productivity (Hales et al. 2009; Marra et al. 1990; Ryan et al. 1999a). Large horizontal and vertical gradients in water properties are associated with the shelfbreak front, a feature susceptible to nonlinear instabilities and strong interactions with Gulf Stream warm-core rings that impinge onto the continental slope (Barth et al. 1998; Gawarkiewicz et al. 2001; Houghton et al. 1994; Linder et al. 2004; Lozier et al. 2002; Ryan et al. 2001). As a result, this region has significant along- and cross-shelf fluxes of heat, salt, nutrients, and carbon that control the characteristics of water masses and the ecosystem both at the shelf break and in the neighboring continental shelf and slope seas (Houghton and Marra 1983; Malone et al.

Corresponding author address: Weifeng Zhang, Woods Hole Oceanographic Institution, 266 Woods Hole Road, MS\#12, Woods Hole, MA 02543.

E-mail:wzhang@whoi.edu
1983; Marra et al. 1982; Vaillancourt et al. 2005). A salient feature of the region is the biomass enhancement along the shelf break (Marra et al. 1990; Ryan et al. 1999b), which is also subject to strong temporal variation (Hales et al. 2009; Ryan et al. 1999a).

Despite numerous studies, both observational (Biscaye et al. 1994; Flagg et al. 2006; Houghton et al. 2009; Walsh et al. 1988) and numerical (Chapman and Lentz 1994; Chen and He 2010; Gawarkiewicz and Chapman 1992), our understanding of the processes that control the circulation and ecosystem dynamics of the shelfbreak front is still inadequate. The primary reason is that shelfbreak processes are inherently nonlinear and exhibit variations over a broad range of spatial and temporal scales. To grapple with this complexity, it is helpful to have a thorough observational description of the mean ocean state around the shelf break. For this purpose, Linder and Gawarkiewicz (1998) combined historical temperature and salinity observations and generated seasonal twodimensional (2D) cross-shelfbreak climatology for subregions of the MAB. Similarly, Fleming and Wilkin (2010) generated a monthly 3D climatology of temperature and salinity for the entire MAB. 


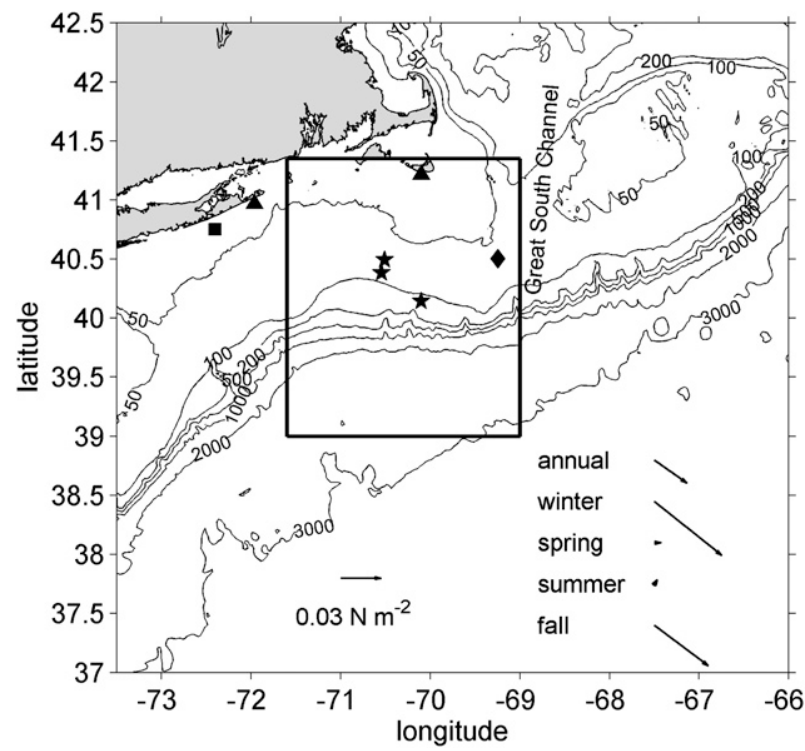

FIG. 1. The study area. The black frame indicates the area over which the 3D climatology is averaged in the along-shelf direction to produce the 2D climatology. Two triangles on the coast indicate locations of tidal gauges; the square indicates location of the current meter that Scott and Csanady (1976) used to estimate the alongshore sea level tilt; the stars are mooring sites; the diamond is NDBC station 44008, where wind observations are used to compute the annual and seasonal mean wind stresses (arrows in the bottom-right corner). In this and all subsequent figures, winter is defined as January-March, spring is defined as April-June, summer is defined as July-September, and fall is defined as OctoberDecember.

The New England shelf break differs from other parts of the MAB shelf break in its orientation (Fig. 1) and is not directly influenced by the major rivers in the MAB. It has been the subject of numerous observational studies (Gawarkiewicz et al. 2004; Houghton et al. 2006; Pickart 2000; Walsh et al. 1988), and yet because of complexities of the circulation many questions in the area remain unanswered. Construction of long-term mooring arrays at the New England shelf break in the near future (i.e., Ocean Observatories Initiative Pioneer Array; Consortium for Ocean Leadership 2010) will provide direct observations of the ocean conditions in the area in unprecedented detail. In this study, we aim to understand the mean circulation in the New England shelfbreak area that can help interpret forthcoming observations and provide a basis for future data-assimilative modeling studies of frontal dynamics and biophysical interaction. Historical observations in the area provide a unique opportunity to calibrate and validate the model. We recognize that circulation on the MAB varies spatially because of varying orientation and width of the continental shelf, as well as localized river inputs (Bush and Kupferman 1980; Hopkins 1982; Mountain 2003), and the shelfbreak circulation presented herein might not be applicable to other parts of the MAB shelf break.

Although shelfbreak circulation is complex, simple models can be useful for understanding fundamental aspects of the circulation, such as frontogenesis (Benthuysen 2010). Because density is approximately uniform in the along-shelf direction (Lentz 2010), we employ a 2D (crossshelf and vertical) model based on the 3D temperature and salinity climatology (Fleming and Wilkin 2010) to examine the annual and seasonal mean circulation around the New England shelf break. Along-shelf variations of temperature and salinity are neglected. However, the along-shelf pressure gradient (PG) generated by alongshelf sea level tilt is included in the model. The advantage of the 2D approach is that complex time-dependent processes at the shelf break, such as instability of the shelfbreak front, can be neglected. In this framework, the influence of external forces, such as wind and the along-shelf pressure gradient, can be examined in isolation.

The paper is organized as follows: Section 2 describes the climatological fields used in this work and also model configuration. The model results are presented in section 3 , and several key points are discussed in section 4 . Conclusions are drawn in section 5 .

\section{Methods}

\section{a. Climatology and velocity observations}

Along-shelf averages of the Fleming and Wilkin (2010) MAB 3D climatology were used to initialize the 2D model. Applying locally weighted quadratic loess smoother (Cleveland and Devlin 1988) to historical observations with anisotropic correlation scales in the cross-shelf and along-shelf directions, Fleming and Wilkin (2010) produced a monthly $3 \mathrm{D}$ climatology of temperature and salinity for the entire MAB. The climatological fields have a horizontal resolution of $0.05^{\circ}$ and a vertical resolution decreasing from $2 \mathrm{~m}$ on the surface to $500 \mathrm{~m}$ at depth. To facilitate the $2 \mathrm{D}$ shelfbreak simulations, we averaged the 3D climatological fields between $71.6^{\circ}$ and $69^{\circ} \mathrm{W}$ (Fig. 1) temporally and spatially in the along-shelf direction to produce annual and seasonal 2D cross-shelf climatologies. The averaging process begins with the mean monotonic cross-shelf bathymetry (Fig. 2), obtained by averaging the 3D bathymetry in the along-shelf direction. Along-shelf averaging of the climatology is then carried out in a depthbinned manner with 2.5 -m bottom depth intervals on the shelf and 5-m bottom depth intervals around the shelf break. For instance, all 3D climatology vertical profiles in the framed area (Fig. 1) within bottom depth range of $78.75-81.25 \mathrm{~m}$ are averaged and assigned to be the vertical profile of the $2 \mathrm{D}$ climatology at bottom depth of $80 \mathrm{~m}$. The annual and seasonal 2D climatological fields 


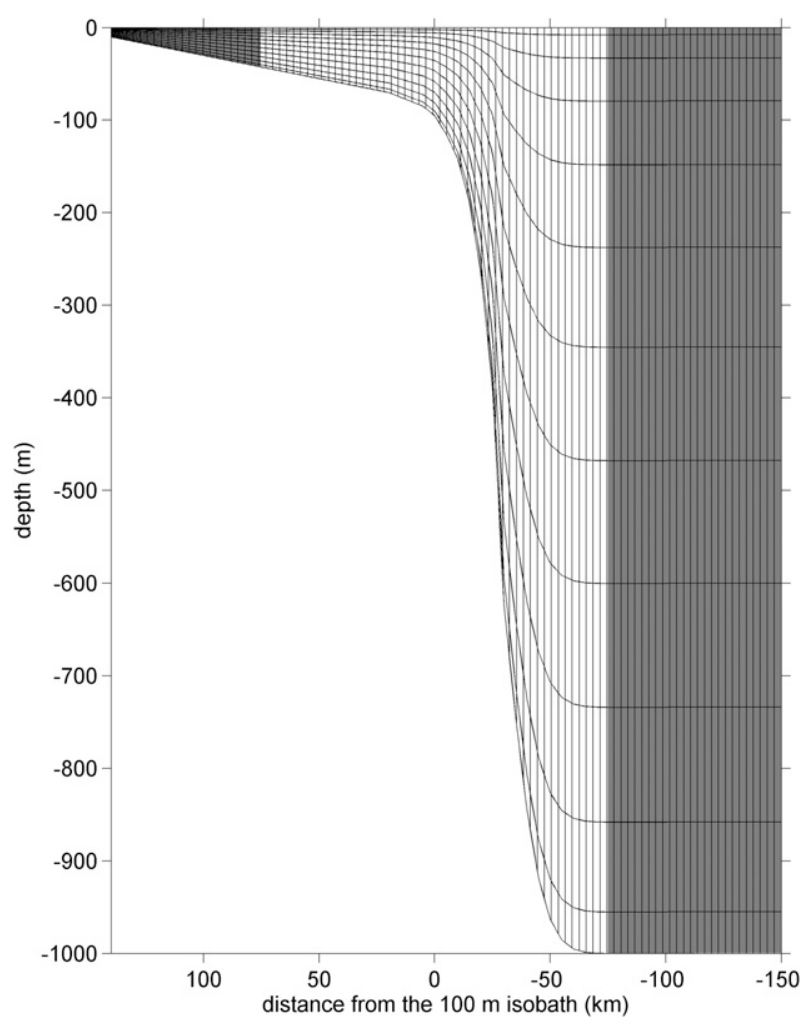

FIG. 2. Cross-shelf topography and model grid. For clear presentation, plotted grids have been decimated and each plotted grid cell consists of $5 \times 5$ model grids. The gray areas are the regions where offshore extension of the 2D climatology (on the offshore side) or smoothed 2D climatology (on the onshore side) is used for model initial conditions and nudging fields.

around the shelf break are shown in Fig. 3 together with computed density and along-shelf current. Here, winter is defined as January-March, spring is defined as AprilJune, summer is defined as July-September, and fall is defined as October-December. The along-shelf current is computed from the density climatology using the thermalwind equation and zero bottom velocity. The temperature and salinity fields in Fig. 3 are smoother than those of Linder and Gawarkiewicz (1998) but contain many of the same features, such as the cold pool, strong summertime stratification, and offshore tilt of the halocline.

The cross-shelf structure of the salinity field varies little over the seasons, whereas that of the temperature field changes dramatically because of formation and destruction of the seasonal thermocline and the underlying cold pool (Fig. 3). The cross-shelf structure of the density field varies with steep middepth isopycnals in winter and relatively flat isopycnals in summer. The isopycnals in all seasons steepen toward the bottom on the shelf. As shown below, this results from offshore buoyancy transport in the bottom boundary layer (BBL). A surface jet is present in all seasons but varies in strength and cross-shelf position.
It is strongest $\left(\sim 12 \mathrm{~cm} \mathrm{~s}^{-1}\right)$ and located farthest offshore in winter, and it is weakest $\left(\sim 7 \mathrm{~cm} \mathrm{~s}^{-1}\right)$ and farthest onshore in summer. The annual mean cross-shelf density gradient on the shelf in the 2D climatology is about $5 \times 10^{-6} \mathrm{~kg} \mathrm{~m}^{-4}$, and the annual mean buoyancy frequency is about $0.012 \mathrm{~s}^{-1}$, both slightly higher than those computed by Lentz (2008b) directly from historical data $\left(4 \times 10^{-6} \mathrm{~kg} \mathrm{~m}^{-4}\right.$ and $0.01 \mathrm{~s}^{-1}$, respectively).

Using time series of historical velocity observations in the MAB longer than 200 days, Lentz $(2008 \mathrm{a}, \mathrm{b})$ presented annual and seasonal mean along-shelf flows on the MAB shelf: all are southwestward increasing with water depth. Extracting those observations located in the framed area in Fig. 1, the cross-shelf distribution of the annual and seasonal mean depth-averaged along-shelf flows (stars in Fig. 4) is similar to that presented in Lentz (2008a,b). Specifically, the along-shelf flow increases gradually in the offshore direction and reaches its peak values at the shelf break (100-150-m water depth). Small differences between seasons exist: the along-shelf flow near the coast is weaker in winter and fall than in the other two seasons, and the along-shelf flow at the shelf break is the strongest in winter. The thermal-wind-balanced along-shelf flows (gray lines in Fig. 4) computed from the density climatology with zero bottom velocity are much weaker than observed in all seasons. The difference is the largest at the shelf break, where it reaches $10 \mathrm{~cm} \mathrm{~s}^{-1}$ in winter.

\section{b. Model configuration}

The Regional Ocean Modeling System (ROMS; http:// www.myroms.org) is used for the shelfbreak simulations. It utilizes a terrain-following coordinate system in the vertical that allows for high resolution in shallow shelf seas and a smooth representation of the steep slope at the shelf break. A redefinition of the barotropic pressure gradient terms in ROMS to account for local variations in density, in conjunction with high-order discretization in the vertical, has greatly reduced pressure gradient truncation errors that have previously hampered terrainfollowing coordinate models in regions of steep bathymetry, such as the New England shelf break. Details of the ROMS computational kernel are described by Shchepetkin and McWilliams $(2005,2008)$.

In the model bathymetry (Fig. 2), the slope is cut off at 1000-m depth and connected smoothly to a flat bottom, which extends $150 \mathrm{~km}$ offshore from the $100-\mathrm{m}$ isobath. In the shoreward direction, the shelf extends with a constant slope to $20-\mathrm{m}$ water depth, $140 \mathrm{~km}$ onshore of the $100-\mathrm{m}$ isobath. This cross section is discretized to 480 uniform intervals in the cross-shelf direction (oriented northsouth) and 60 stretched vertical layers with higher resolution (about $0.2 \mathrm{~m}$ at the shelf break) toward the surface and the bottom. The onshore (northern) boundary 


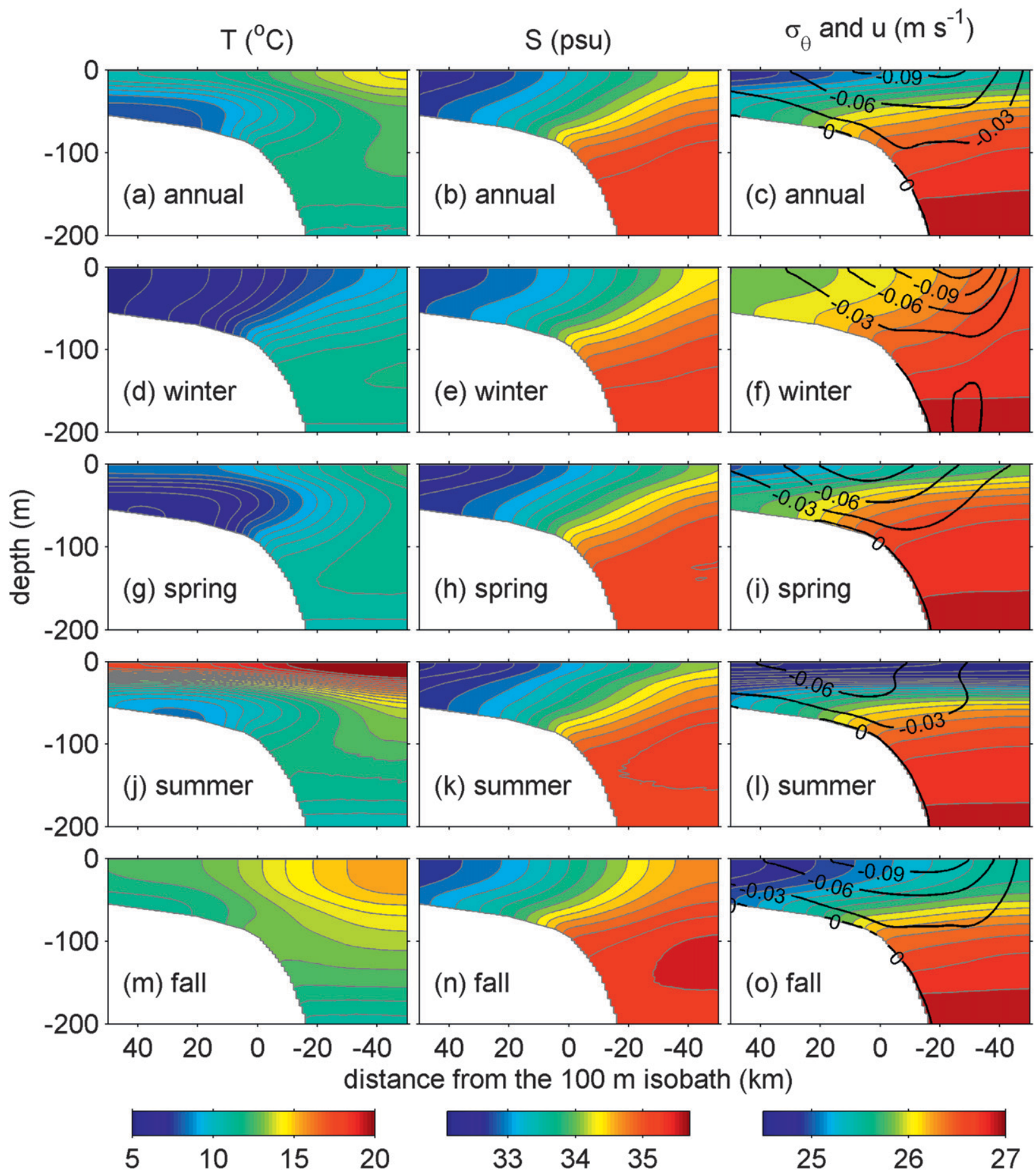

FIG. 3. Annual and seasonal 2D climatology around the shelf break. (right) Black contours are the thermal-wind-balanced along-shelf velocity computed from the $2 \mathrm{D}$ climatology with zero bottom velocity.

on the shelf is a solid wall. The offshore (southern) boundary is open with Chapman (1985) and Flather (1976) conditions used for sea level elevation and barotropic velocity, respectively, and an Orlanski-type radiation condition (Orlanski 1976) for momentum, temperature, and salinity. In the along-shelf direction (east-west), there are five grid points with $600-\mathrm{m}$ resolution and periodic boundary conditions. The generic length scale (GLS) method $k-k l$ closure (Umlauf and Burchard 2003) is used for the vertical mixing and quadratic 


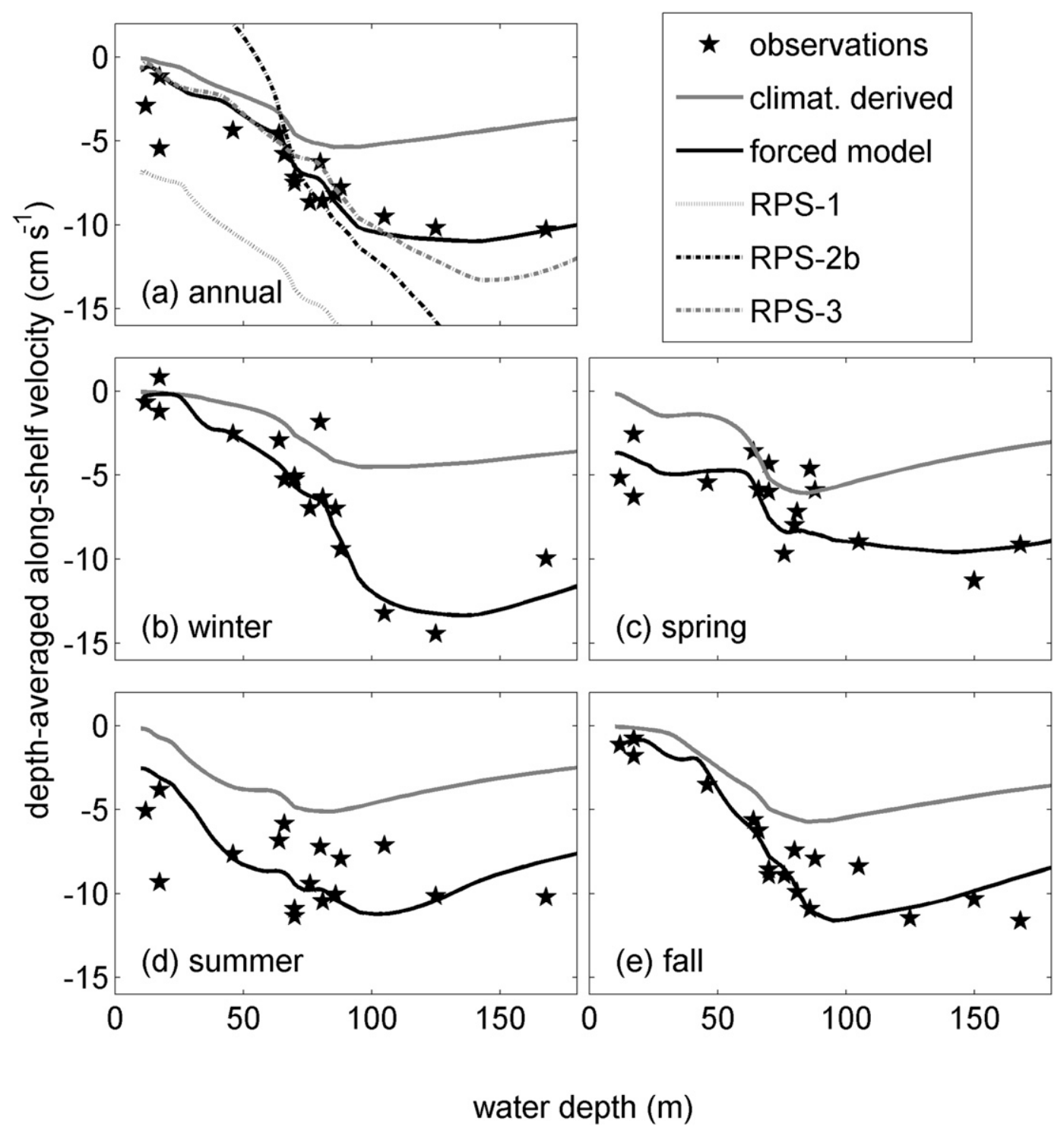

FIG. 4. Cross-shelf distribution of the observed (stars), thermal-wind-balanced (gray solid lines), and modeled (black lines) depth-averaged along-shelf velocity in different seasons. (a) Depth-averaged along-shelf velocity obtained from reduced-physics simulations are also shown: RPS-1 is the reduced-physics simulation without wind; RPS$2 \mathrm{~b}$ is the simulation with uniform along-shelf PG (the equivalent sea level tilt is $3.7 \times 10^{-8}$ ); and RPS-3 is simulation without nudging. Depth-averaged along-shelf velocity from the simulation without along-shelf PG (RPS-2a) is stronger than $2 \mathrm{~cm} \mathrm{~s}^{-1}$ over the entire shelf and off the scale of the plot.

bottom drag is used with a constant drag coefficient. Test simulations with different GLS closure schemes indicate that the modeled result is not sensitive to the choice of vertical mixing scheme. The quadratic bottom drag coefficient associated with velocity $0.1 \mathrm{~m}$ above the bottom (half height of the bottom cells) is about 0.003 (Fig. B1 in Lentz 2008a). The omission of tides in the model reduces the effective bottom drag. Test simulations with and without tides suggest that tides increase the bottom root-mean-square velocity at the shelf break by a factor of 2. We therefore increase the quadratic drag coefficient fourfold to 0.012 to compensate for the missing effect of tides in the model.

Because the largest model error is expected to be the pressure gradient truncation error at the shelf break, we conducted test simulations with flat stratification and no external forcing to quantify model error around the steep topography and confirm the applicability of ROMS in this shelfbreak application. Seasonal stratification at the shelf break is extended over the entire model domain and used to initialize the test simulations. Because the summertime stratification is the strongest among the seasons, that 
simulation has the largest pressure gradient error and generates the strongest spurious current. After 200 days (the time period of diagnostic simulations), the model generates a spurious current at the shelf break of $1 \times 10^{-3} \mathrm{~m} \mathrm{~s}^{-1}$ and $5 \times 10^{-5} \mathrm{~m} \mathrm{~s}^{-1}$ in along- and cross-shelf directions, respectively. They are $2 \%-5 \%$ of the mean currents resolved by the summer climatological simulation (see section $3 b$ ). Spurious currents in models of other seasons are much smaller than $2 \%$ of the corresponding mean currents.

The annual and seasonal simulations are initialized in the cross-shelf direction with the 2D temperature and salinity climatology, the thermal-wind-balanced along-shelf velocity, zero cross-shelf and vertical velocity, and geostrophically balanced sea level (gray lines in the first column of Fig. 5). To diminish variations next to the coast and in the deep sea that are irrelevant to circulation at the shelf break, we smooth the climatological fields onshore of the 40-m water depth (75 km from the 100-m isobath) and extend uniformly in the offshore direction the climatological fields at $75 \mathrm{~km}$ offshore of the 100-m isobath to the offshore boundary (gray areas in Fig. 2). The initial conditions are uniform in the along-shelf direction. To compensate for the missing of some $3 \mathrm{D}$ processes in the $2 \mathrm{D}$ model and diagnose the mean circulation pattern consistent with the density climatology, we nudge temperature and salinity toward the climatology with a 2-day time scale over the course of each simulation. Other model state variables are free to evolve dynamically and gradually reach a steady state during the 200 days of simulation in each case. We will show in section 4 that the 2D nudged simulation gives a circulation pattern similar to a full 3D simulation without nudging and that patterns in the nudging terms can be identified with some of the $3 \mathrm{D}$ processes that are missing in the $2 \mathrm{D}$ simulations.

The model has no heat or salt exchange with the atmosphere but is forced by annual and seasonal mean wind stresses, which are computed from observations at $\mathrm{Na}$ tional Data Buoy Center (NDBC) buoy 44008 (Fig. 1). Because the mean along-shelf density gradient is approximately zero on the shelf (Lentz 2010), the baroclinic along-shelf pressure gradient is negligible. As we will show later, bottom stress over the shelf is relatively small in the vertically integrated momentum equation. The only force that can balance the wind stress in the alongshelf direction and keep the along-shelf flow structure as observed (stars in Fig. 4) is the barotropic along-shelf pressure gradient generated by along-shelf sea level tilt. Using a linear model, Lentz (2008b) estimated the alongshelf sea level tilt on the MAB shelf to be $3.7 \times 10^{-8}$ at midshelf. Along-shelf homogeneity in our 2D formulation is achieved by the application of periodic boundary conditions, and therefore the model cannot represent the along-shelf sea level tilt directly. Instead, we impose an along-shelf body force which varies across-shelf and is tuned to match the modeled depth-averaged along-shelf currents with observations in each case. As will be seen below, the imposed along-shelf pressure gradient intensifies the along-shelf flow over the whole water column, including the bottom layer, which strengthens the bottom stress. The bottom stress together with along-shelf pressure gradient force balances the wind stress (Fig. 5, right). We note here that addition of the cross-shelf varying alongshelf pressure gradient in a truly 2D system causes an imbalance in along-shelf (cross shelf) gradient of the crossshelf (along shelf) momentum equation. But, as will be elaborated in detail in section 4, its effects on the momentum balance are negligible in our 2D model, but it is essential to simulate the observed along-shelf currents.

\section{c. Governing equations}

Defining positive $x$ direction as along-shelf eastward, positive $y$ as onshore (consistent with the orientation of the New England shelf; Fig. 1), and positive $z$ as upward, the steady-state momentum equations are

$$
\begin{aligned}
& u \frac{\partial u}{\partial x}+v \frac{\partial u}{\partial y}-f v=-g \frac{\partial \eta}{\partial x}-\frac{g z}{\rho_{0}} \frac{\partial \rho}{\partial x}+\frac{1}{\rho_{0}} \frac{\partial \tau_{x}}{\partial z} \text { and } \\
& u \frac{\partial v}{\partial x}+v \frac{\partial v}{\partial y}+f u=-g \frac{\partial \eta}{\partial y}-\frac{g z}{\rho_{0}} \frac{\partial \rho}{\partial y}+\frac{1}{\rho_{0}} \frac{\partial \tau_{y}}{\partial z},
\end{aligned}
$$

where $u$ and $v$ are the $x$ and $y$ velocity components, $f$ is Coriolis parameter, $g$ is gravitational acceleration, $\eta$ is the sea level elevation, $\rho_{0}$ is the characteristic density, and $\tau_{x}$ and $\tau_{y}$ are the $x$ and $y$ components of the stress. The continuity equation is

$$
\frac{\partial u}{\partial x}+\frac{\partial v}{\partial y}+\frac{\partial w}{\partial z}=0
$$

where $w$ is vertical velocity. Neglecting along-shelf variation in all variables but $\eta$ and considering the wall boundary on the coast, the depth-integrated momentum equations can be written as

$$
\begin{aligned}
\int_{-h}^{\eta}\left(v \frac{\partial u}{\partial y}\right) d z= & -g H \frac{\partial \eta}{\partial x}+\frac{1}{\rho_{0}}\left(\tau_{x}^{s}-\tau_{x}^{b}\right) \quad \text { and } \\
\int_{-h}^{\eta}\left(v \frac{\partial v}{\partial y}\right) d z+f H U= & -g H \frac{\partial \eta}{\partial y}-\int_{-h}^{\eta}\left(\frac{g z}{\rho_{0}} \frac{\partial \rho}{\partial y}\right) d z \\
& +\frac{1}{\rho_{0}}\left(\tau_{y}^{s}-\tau_{y}^{b}\right)
\end{aligned}
$$

where $H=h+\eta$ is the total water depth; $U=$ $(1 / H) \int_{-h}^{\eta} u d z$ is the depth-averaged along-shelf velocity; and $\tau^{s}$ and $\tau^{b}$ are the surface and bottom stresses, respectively. In the model, $\tau^{b}=C_{d}\left|\mathbf{u}_{b}\right| \mathbf{u}_{b}$, where $C_{d}=0.012$ is 

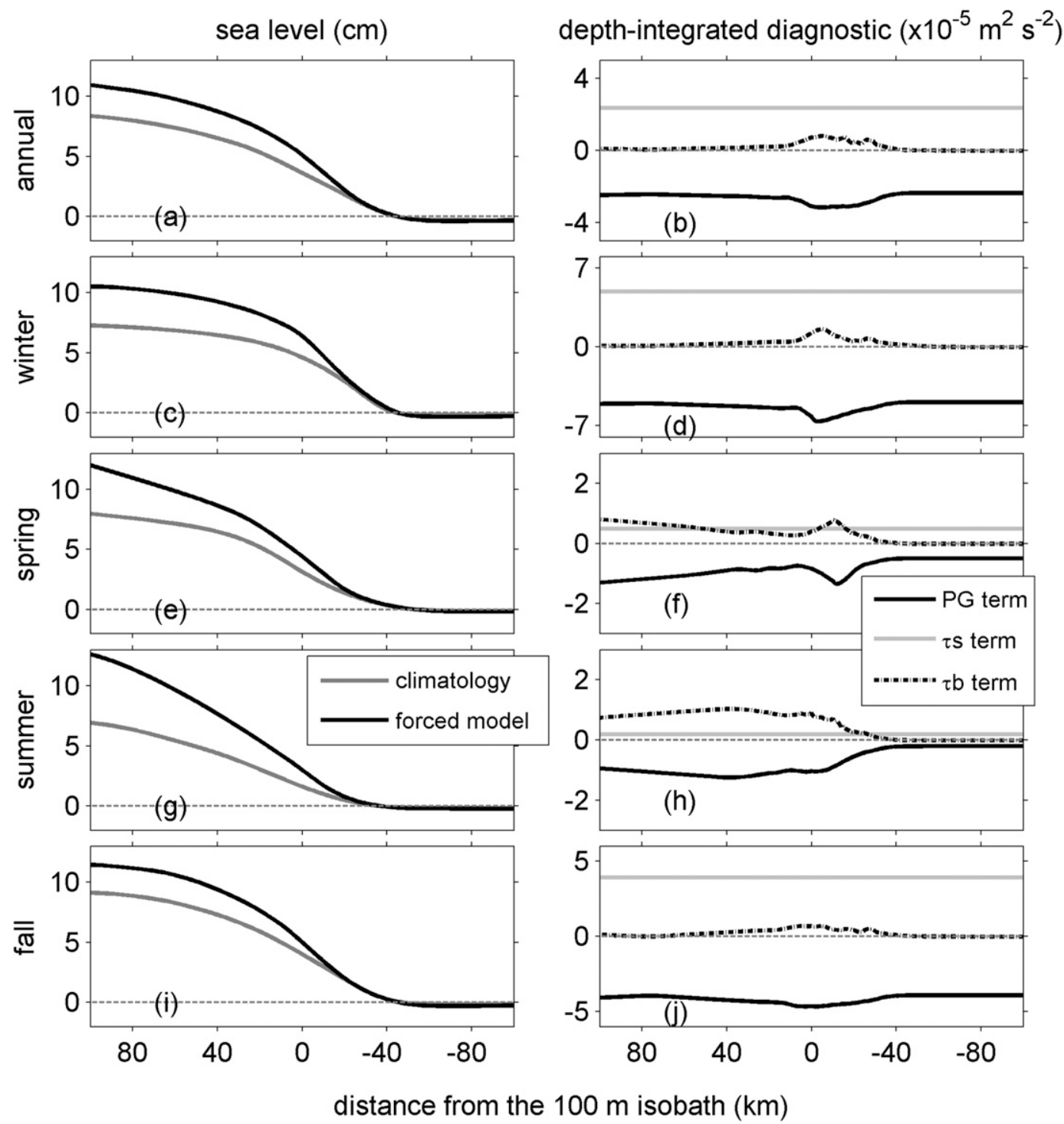

FIG. 5. Cross-shelf distribution of (left) the sea surface height and (right) the major terms in depth-integrated along-shelf momentum balance in different seasons. The sea surface height is computed from the $2 \mathrm{D}$ climatology (gray lines) and given by the 2D simulations (black lines). (right) Black solid lines depict the PG term; gray lines denote the surface stress $\left(\tau_{s}\right)$ term; and black dashed lines denote the bottom stress $\left(\tau_{b}\right)$ term.

the drag coefficient (see section $2 \mathrm{~b}$ for the discussion of the value of $C_{d}$ ) and $\mathbf{u}_{b}$ is the vector form of bottom velocity. The continuity equation becomes

$$
\frac{\partial v}{\partial y}+\frac{\partial w}{\partial z}=0
$$

\section{Results}

\section{a. Annual mean circulation}

The steady-state along-shelf momentum balance in the annual mean simulation (Fig. 6) is mainly a superposition of the surface and bottom Ekman dynamics and an interior geostrophic balance. The dominant balance is reflected in (4), where the surface and bottom stress terms together balance the pressure gradient term (Fig. 5b). Hereby, (4) becomes

$$
\frac{1}{\rho_{0}}\left(\tau_{x}^{s}-\tau_{x}^{b}\right) \approx g H \frac{\partial \eta}{\partial x} .
$$

However, the bottom stress term in (7) is small everywhere and noticeable only in the vicinity of the shelf break (Fig. 5b). The principal balance between surface wind stress and along-shelf pressure gradient agrees with 


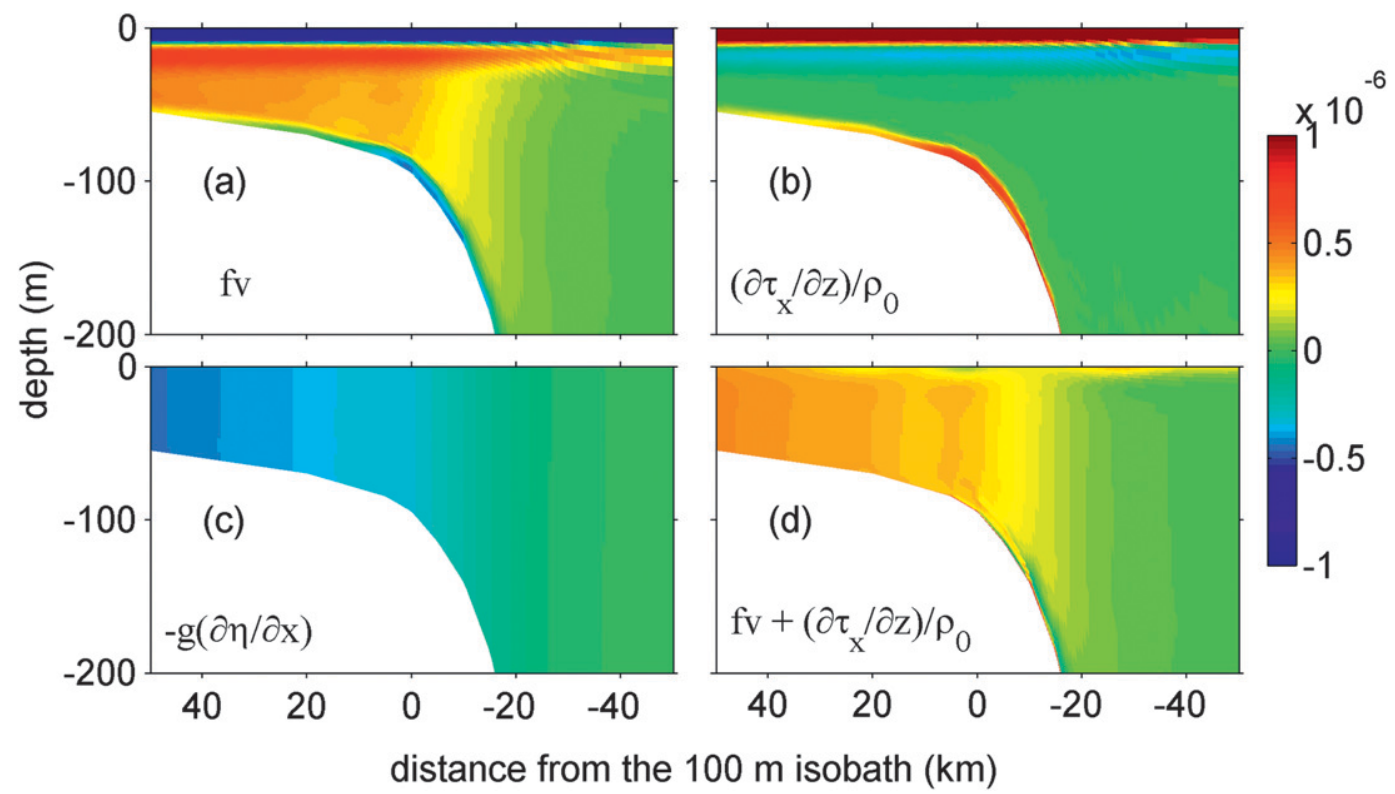

FIG. 6. Cross section of the major terms in the along-shelf momentum balance $\left(\mathrm{m} \mathrm{s}^{-2}\right)$.

previous studies in the area (Csanady 1976; Hopkins 1982; Shearman and Lentz 2003; Stommel and Leetmaa 1972). We note here that tidal rectification, an important process over the inner shelf, is missing in the $2 \mathrm{D}$ model. Although its absence may be significant near the coast, we do not expect it to play a major role at the shelf break. In any case, the New England shelf in this region is a local minimum for the amplitude of $M_{2}$ tide (Moody et al. 1984). Another missing process is internal tides. Although their net effect on the mean density distribution is intrinsic to the nudging toward climatology, their impact on the mean momentum balance is unclear at this point and neglected in the model. The steady-state cross-shelf momentum balance (Fig. 7) is predominantly geostrophic, and a secondary Ekman balance exists in the surface boundary layer. Note that the cross-shelf pressure gradient force, the first two terms in the right-hand side of (2), is generated by both the cross-shelf sea level tilt and the cross-shelf density gradient.

The along-shelf sea level tilt $\partial \eta / \partial x$ inferred from the tuned along-shelf pressure gradient increases shoreward (Fig. 8). It results from a balance between $\tau_{x}^{s} / \rho_{0}$ and $g H \partial \eta /$ $\partial x$ in (7) and is consistent with historical analysis of the locally forced $\partial \eta / \partial x$ in the MAB (Hopkins 1982). Essentially, $\partial \eta / \partial x$ increases onshore to counter the change in water depth; the sudden transition of $\partial \eta / \partial x$ at the shelf break also corresponds to the change in bathymetry. The modeled annual mean $\partial \eta / \partial x$ on the midshelf and outer shelf of about $4 \times 10^{-8}$ agrees with the value estimated by Lentz (2008b) (star in Fig. 8), based on multiseasonal time series of observed velocity, and historical estimates of the mean MAB along-shelf surface slope on the order of $10^{-7}-10^{-8}$ (Beardsley and Winant 1979; Csanady 1976; Hopkins 1982; Stommel and Leetmaa 1972).

Tuning $\partial \eta / \partial x$ to observations accelerates and sharpens the jet at the shelf break (maximum velocity increases from 10 to $16 \mathrm{~cm} \mathrm{~s}^{-1}$ ) (cf. Figs. 3c, 9a). The increase of the along-shelf velocity $u$ strengthens the cross-shelf Coriolis force, which raises sea level farther in the onshore direction because of the cross-shelf geostrophic balance. Because the intensification of $u$ is over the whole water column, the along-shelf bottom velocity $u_{\mathrm{b}}$ is increased from zero to $2.5 \mathrm{~cm} \mathrm{~s}^{-1}$ at the shelf break (black line in Fig. 10a). Consequently, the bottom stress term $-\tau_{x}^{b} / \rho_{0}$ at the shelf break is enhanced, which, together with $\tau_{x}^{s} / \rho_{0}$, balances $g H \partial \eta / \partial x$ in (7) (Fig. 5b).

The modeled cross-shelf velocity (Fig. 9b) resembles observations in the area (Fig. 6c in Lentz 2008b): an interior onshore flow sandwiched by a surface and a bottom offshore flow. Flows in the surface and bottom layers are primarily driven by Ekman dynamics associated with the wind and bottom stress, respectively (Fig. 6). Here, we define the bottom layer as the vertical extent of the offshore flow near the bottom. The thickness of the bottom layer varies between 5 and $10 \mathrm{~m}$ and is thickest at the 100-m isobath (Fig. 10b); the vertically averaged crossshelf velocity in the bottom layer is about $4 \mathrm{~mm} \mathrm{~s}^{-1}$ at the shelf break and gradually decreases in the offshore direction (Fig. 10c). This trend differs from some historical observations (Fig. 8 in Lentz 2008a) where near-bottom cross-shelf velocity $v_{b}$ sometimes increases in the offshore direction and reaches a peak $\left(3-5 \mathrm{~cm} \mathrm{~s}^{-1}\right)$ at $250-\mathrm{m}$ 


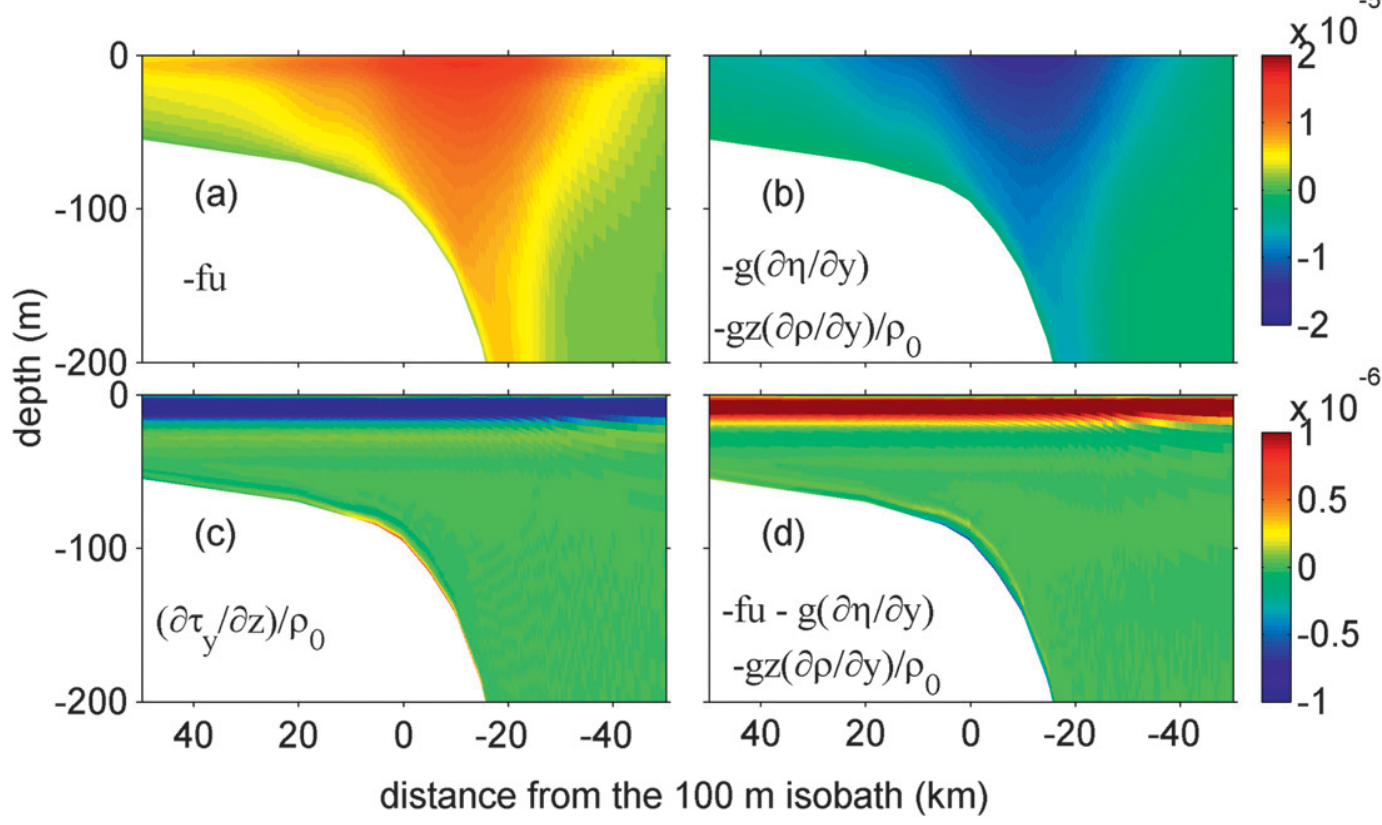

FIG. 7. Cross section of the major terms in the cross-shelf momentum balance $\left(\mathrm{m} \mathrm{s}^{-2}\right)$.

bottom depth. The cause of this discrepancy is unknown at this point. However, the thickness of the simulated bottom boundary layer is roughly consistent with that estimated from the BBL thickness formula (star in Fig. $10 \mathrm{~b}), h=f v_{I} /\left(\alpha N^{2}\right)$ (Trowbridge and Lentz 1991), where $v_{I}$ is the interior along-shelf velocity, $\alpha$ is the bottom slope, and $N$ is buoyancy frequency.

Because of the along-shelf geostrophic balance, the interior cross-shelf flow $v_{I}$ is shoreward (Fig. 9b) and increases at the shelf break along with $\partial \eta / \partial x$. The winddriven Ekman velocity changes direction with depth (Ekman spiral) and, at 25-m depth, it aligns with the geostrophic onshore flow, resulting in a peak of the interior onshore flow just below the surface layer. This peak is absent in a temporally averaged vertical profile of the observed cross-shelf velocity (Fig. 6c in Lentz 2008b). Its absence could result from incomplete equilibration of the ocean interior to fluctuating wind stress, in contrast to the steady forcing used in this climatological simulation. In any case, this peak has little effect on the overall solution. The onshore increase of $v_{I}$ results in positive $\partial v / \partial y$ in (6) and gives rise to upwelling around the shelf break (Fig. 9c). The upward motion strengthens linearly from zero at the surface to about $1.5 \mathrm{~m} \mathrm{day}^{-1}$ at $100-\mathrm{m}$ depth, much slower than episodic 4-9 $\mathrm{m} \mathrm{day}^{-1}$ upwelling inferred from observations at the New England shelf break (Barth et al. 1998; Houghton and Visbeck 1998). However, the mean upwelling that the climatological simulation represents can still be a potential mechanism to bring nutrients to the euphotic zone and stimulate local biological production. The effects of the climatological upwelling on biological production around the shelf break are the subject of ongoing research and will be reported in the future.

To illustrate the contributions of various external forces on the mean circulation, we conducted a series of reducedphysics simulations (RPS) with each of these forces (wind, along-shelf pressure gradient, and nudging) removed individually from the baseline annual mean simulation. The

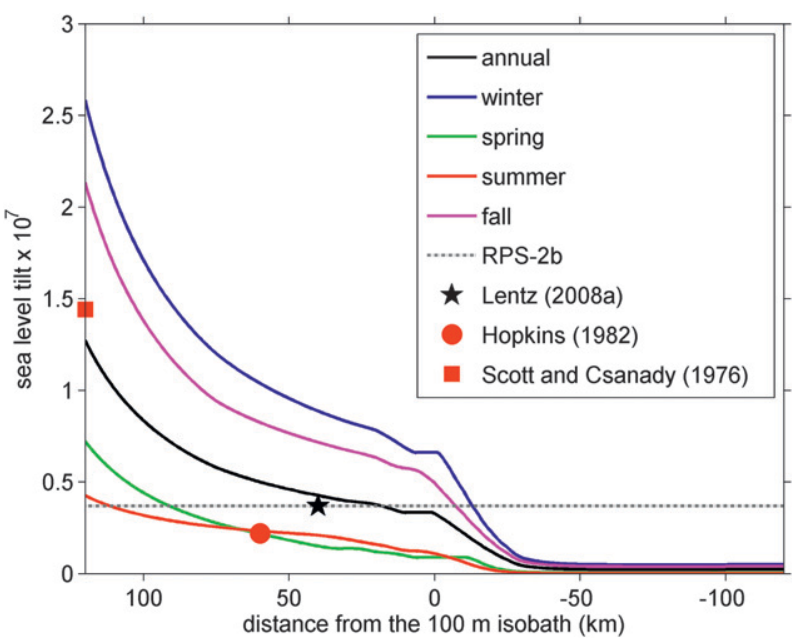

FIG. 8. Cross-shelf distribution of the along-shelf sea level tilt associated with the along-shelf PGs imposed in different simulations. Symbols show the annual mean (star) and summer mean (circle and square) along-shelf sea level tilt obtained from literature. 


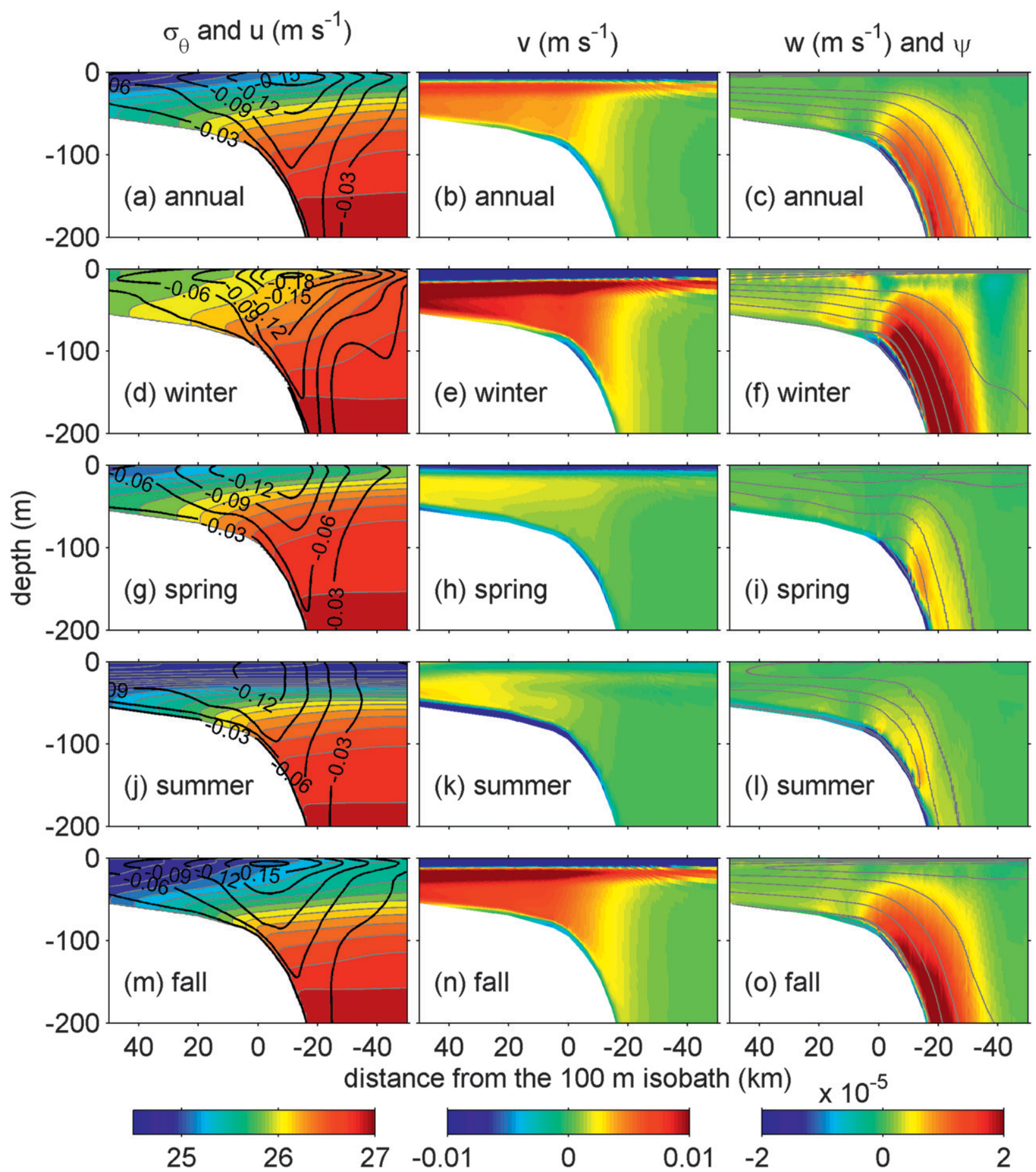

FIG. 9. (left) Density (color contour) and along-shelf velocity (black contour), (middle) cross-shelf velocity, and (right) vertical velocity given by simulations of different seasons. Lines in the right column are some selected stream lines.

simulations are named RPS-1, RPS-2a, and RPS-3, respectively. To demonstrate the effect of having the cross-shelf varying $\partial \eta / \partial x$, we conducted another simulation (RPS2b) with uniform $\partial \eta / \partial x$ of $3.7 \times 10^{-8}$, the value estimated by Lentz (2008b) (gray dashed-dotted line in Fig. 8).
Without wind stress, a strong westward along-shelf flow is generated (Figs. 4a, 11a). Meanwhile, $u_{b}$ at the shelf break is strengthened from $3 \mathrm{~cm} \mathrm{~s}^{-1}$ in the baseline simulation to $6 \mathrm{~cm} \mathrm{~s}^{-1}$, and $-\tau_{x}^{b} / \rho_{0}$ is therefore enhanced substantially to counterbalance $g H \partial \eta / \partial x$ in (7). Accordingly, 


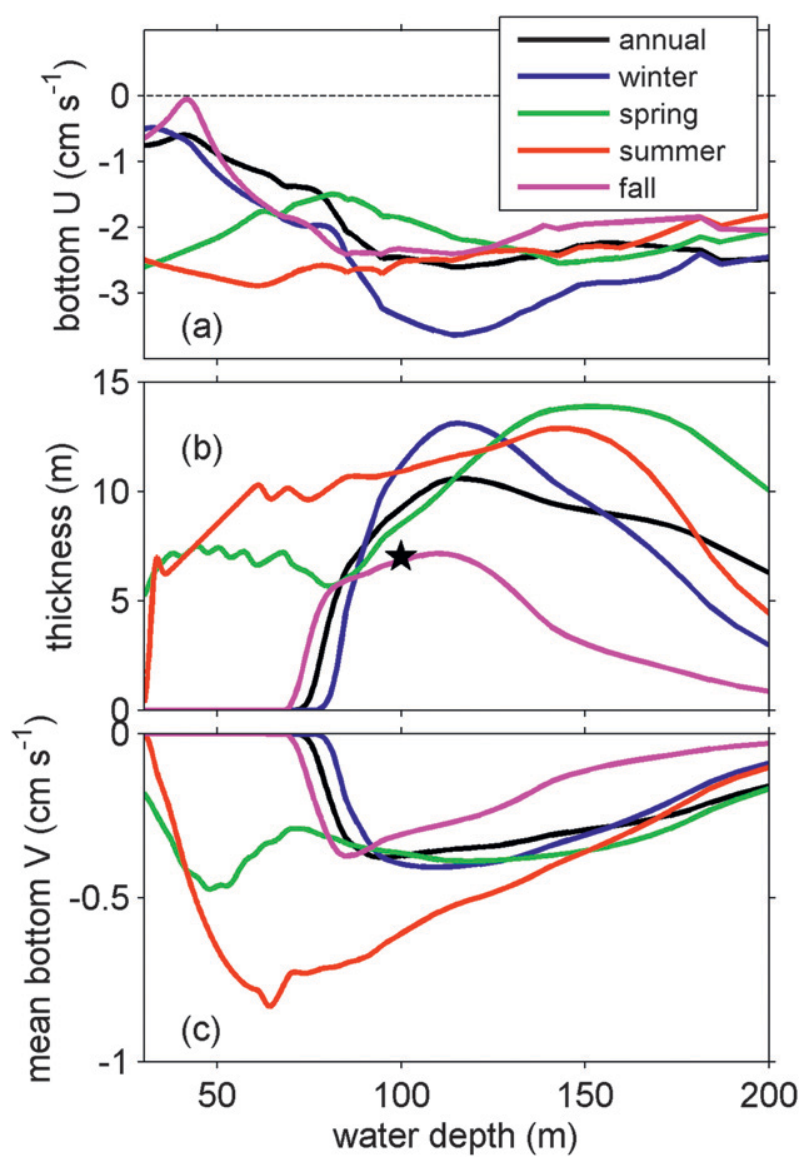

FIG. 10. (a) Cross-shelf distribution of along-shelf bottom velocity, (b) thickness of the offshore-flowing bottom layer, and (c) mean cross-shelf velocity in the bottom layer in different seasons. The star in (b) depicts the thickness of the BBL computed with a formula given by Trowbridge and Lentz (1991).

$v_{\mathrm{b}}$ is strengthened (Fig. 11b), which compensates for the lack of surface offshore Ekman flow and balances the onshore interior volume flux. Despite the changes in the surface and bottom layers, patterns of the onshore interior flow and the shelfbreak upwelling (Figs. 11b,c) remain similar to the baseline case.

With $\partial \eta / \partial x=0$ (RPS-2a), $u$ over the entire shelf becomes eastward (Fig. 11d). In the cross-shelf direction, the most striking change is the reverse of $v_{\mathrm{b}}$ (Fig. 11e), resulting from the reverse of $u_{\mathrm{b}}$. The corresponding negative $\tau_{x}^{b}$ balances the $\tau_{x}^{s}$ in this case. As such, the interior onshore flow and the shelfbreak upwelling mostly disappear. Differences between the baseline simulation and RPS-2a prove that the onshore interior flow, offshore bottom flow, and shelfbreak upwelling are primarily driven by the along-shelf pressure gradient. With the uniform $\partial \eta / \partial x$ (RPS-2b), water onshore of the 60-m isobath moves eastward and water offshore of the 75-m isobath moves westward at a speed much faster than observed (Fig. 4a; similar to Fig. 3 in Lentz 2008a). Meanwhile, patterns of $v$ and $w$ at the shelf break become irregular (Figs. 11h,i). The discrepancy between RPS-2b and the observed $U$ demonstrates the necessity of prescribing cross-shelf variations in the along-shelf pressure gradient, as suggested by Hopkins (1982).

When nudging is removed (RPS-3), the structure of the along-shelf flow (Figs. 4a, 11j) remains similar to the baseline simulation, but the onshore interior flow raises the interior isopycnals. Symmetric instability (Allen and Newberger 1998) in the bottom layer is generated in the form of a chain of shoreward-moving recirculation cells. The recirculation cells span $10-50 \mathrm{~m}$ in the vertical and $4 \mathrm{~km}$ horizontally with flows of about $1 \mathrm{~cm} \mathrm{~s}^{-1}$ detaching and reattaching to the bottom boundary layer. In the baseline case, nudging toward climatology suppresses the steepening of the isopycnals in the bottom layer and prevents the generation of negative potential vorticity in the bottom layer, a necessary condition of forming symmetric instability.

\section{b. Seasonal variation of the shelf circulation}

Strong seasonal variation is present in the shelf circulation, and as such it is necessary to tune $\partial \eta / \partial x$ to match the modeled $U$ to the observations in different seasons (Fig. 4). Because of seasonal variation of the wind (Fig. 1 ), the tuned $\partial \eta / \partial x$ is highest in winter and weakest in summer. Because $U$ changes relatively little over the seasons (Fig. 4) compared to seasonal variation of $\tau^{s}$, there is relatively little seasonal variation in $u_{\mathrm{b}}$. Consequently, the seasonal change in $\tau_{x}^{b}$ is unable to counterbalance the large seasonal variation of $\tau_{x}^{s}$ in (7). Because the nonlinear terms are negligible and $\partial \rho / \partial x$ is too small (Lentz 2010), $g H \partial \eta / \partial x$ has to vary seasonally to counter the seasonal change of $\tau_{x}^{s}$ in (7). The resultant $\partial \eta / \partial x$ is around $0.2 \times 10^{-7}$ in summer and $0.8-2.5 \times 10^{-7}$ in winter (Fig. 8). The summer value is very close to the wind-driven $\partial \eta / \partial x$ estimated by Hopkins (1982) $\left(0.23 \times 10^{-7}\right.$; red circle in Fig. 8$)$ on the shelf southwest of our study area. The winter value differs significantly from that estimated by Hopkins $(-0.039 \times$ $10^{-7}$ ) because of different values for seasonal wind stresses being used. Applying Hopkins's formula with our mean wind stress yields $\partial \eta / \partial x$ of $0.5 \times 10^{-7}$ at the shelf break, which is very close to our estimate. Close to the coast, the summertime $\partial \eta / \partial x$ is about $5 \times 10^{-8}$, which is 3 times smaller than that estimated by Scott and Csanady (1976) (red square in Fig. 8) from a 25-day summertime current record near Long Island (square in Fig. 1). The difference in the modeled alongshore sea level tilt between summer and winter reaches about $2.2 \times 10^{-7}$ (Fig. 8). We analyzed a 20-yr (1990-2009) time series of sea level at Nantucket Island (NDBC station NTKM3-8449130) and Montauk, Long Island (NDBC station MTKN6-8510560) (see Fig. 1 


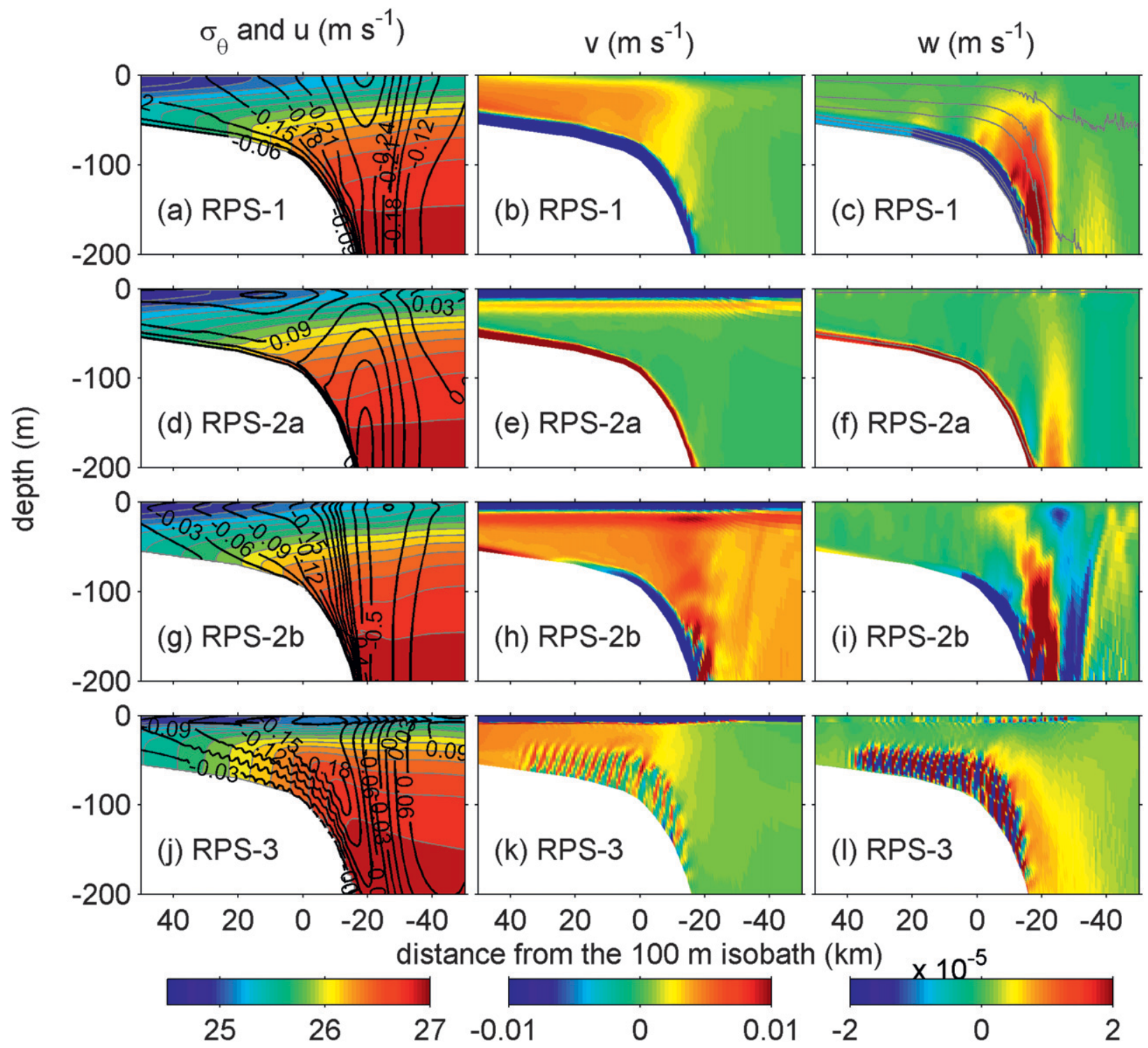

FIG. 11. (left) Density (color contour) and along-shelf velocity (black contour), (middle) cross-shelf velocity, and (right) vertical velocity given by different reduced-physics simulations. (c),(f) Lines show some selected stream lines. RPS-1 is the simulation without wind, RPS$2 \mathrm{a}$ is the simulation without along-shelf PG, RPS-2b is the simulation with uniform along-shelf PG (equivalent sea level tilt of $3.7 \times 10^{-8}$ ), and RPS-3 is the simulation without nudging.

for station positions), and obtained a summer-winter difference in alongshore sea level tilt of $2.16 \times 10^{-7}$, consistent with the modeled result. Ullman and Codiga (2004) obtained a seasonal variation of the along-shelf sea level tilt of about $2 \times 10^{-7}$ (Fig. 12a in Ullman and Codiga 2004), based on HF radar and acoustic Doppler current profiler observations in the Long Island Sound outflow region over a 2 -yr period.

Seasonal variation is also present in the along-shelf, cross-shelf, and vertical velocities at the shelf break (Fig. 9). They constitute meaningful changes of the shelfbreak circulation, because they are more than an order of magnitude larger than model spurious currents (section $2 b$ ). The modeled shelfbreak jet reaches its peak strength $\left(22 \mathrm{~cm} \mathrm{~s}^{-1}\right)$ in winter and weakest flow $\left(13 \mathrm{~cm} \mathrm{~s}^{-1}\right)$ in summer, consistent with observed seasonality of the shelfbreak jet in the MAB south of the study area (Flagg et al. 2006). The modeled seasonal difference of the strength of the along-shelf jets $\left(9 \mathrm{~cm} \mathrm{~s}^{-1}\right)$ is larger than that computed from the 2D climatology with the thermalwind equation $\left(5 \mathrm{~cm} \mathrm{~s}^{-1}\right.$; Fig. 3). Changes of the crossshelf density gradient $\partial \rho / \partial y$ account for about half of the seasonal variation of the jet strength. The other half is consistent with the seasonal variation of $u_{\mathrm{b}}$ (Fig. 10a) 


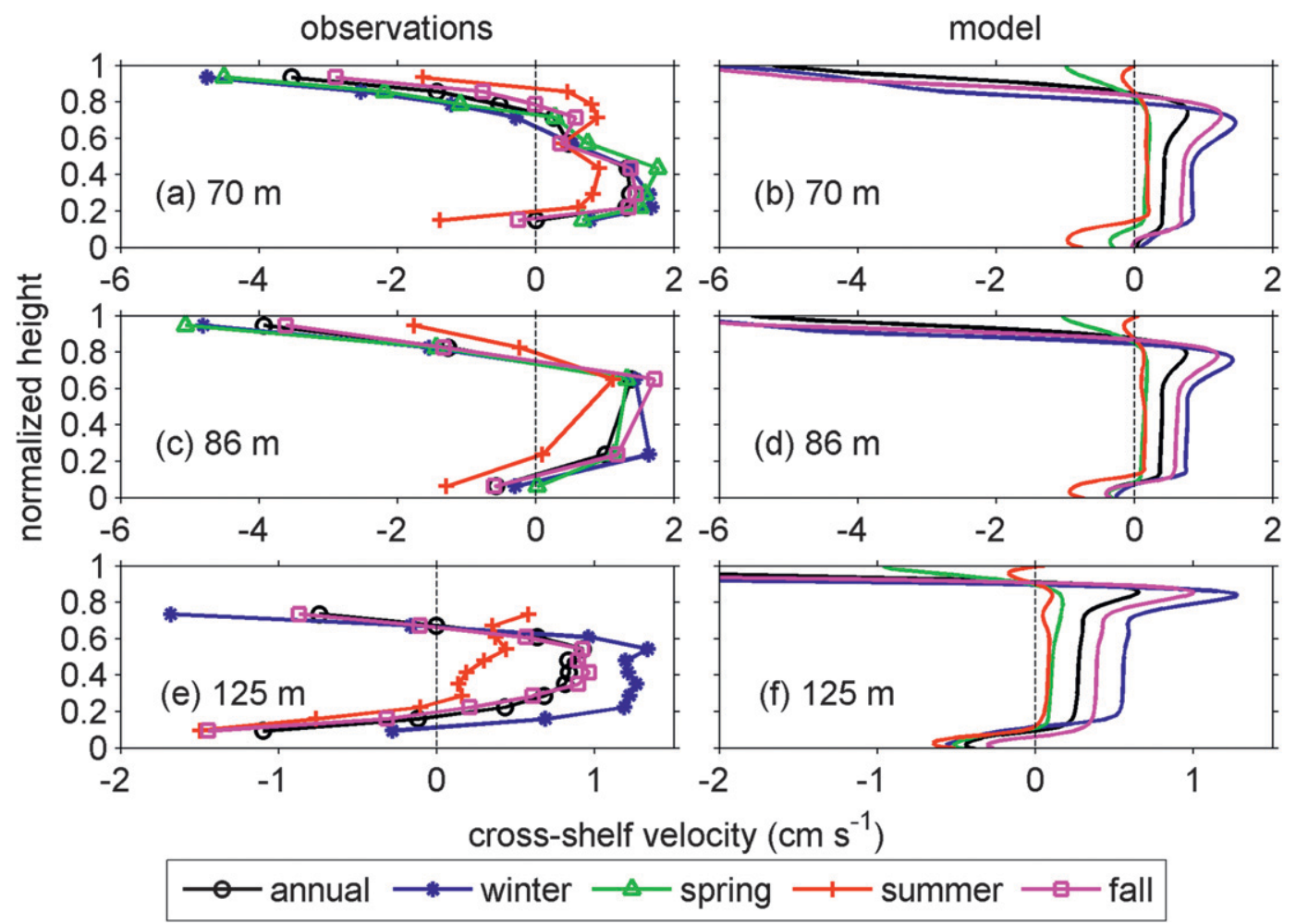

FIG. 12. (left) Observed and (right) modeled cross-shelf velocity at three mooring sites.

and is therefore barotropic. It results from seasonal change of $\tau_{x}^{b}$, which is needed to balance $\tau_{x}^{s} / \rho_{0}-g H \partial \eta / \partial x$ in (7). Because of geostrophy, the aforementioned seasonal variation of $\partial \eta / \partial x$ drives seasonal variations in $v_{I}: v_{I}$ at the $100-\mathrm{m}$ isobath is strongest $\left(1.5 \mathrm{~cm} \mathrm{~s}^{-1}\right)$ in winter and the weakest $\left(0.25 \mathrm{~cm} \mathrm{~s}^{-1}\right)$ in summer (Fig. 9). Because $v_{\mathrm{I}}$ in the deep sea is small, there is a stronger onshore intensification of $v_{I}$ at the shelf break in winter than in summer. From (6), the upwelling at the shelf break is strongest in winter and the weakest in summer.

To validate the seasonal variation of the shelfbreak circulation, we compare vertical profiles of the modeled cross-shelf velocity with their observed counterparts at three mooring sites in the study area (Fig. 12). The mooring sites (see Fig. 1 for their locations) are at 70-, 86-, and 125-m shelf depths, respectively, and recorded vertical profiles of the velocity for about a 1-yr period (the first two sites were August 1996-May 1997 and the last one was December 1995-February 1997) (Lentz 2008b). The numbers of discrete vertical measurements at the three sites are 9, 5, and 11, respectively. Figure 12 shows some general similarities and some detailed discrepancies between the modeled and observed cross-shelf velocity profiles. First, the modeled cross-shelf velocity resembles the observed three-layer structure at all three sites for all seasons. However, the relative depths of the layers and the vertical distribution of the flow within each layer are different between the models and observations. Second, models and observations show similar seasonal variation of the offshore $v_{b}$ : strong in summer and weak in winter (also see Fig. 10c). The offshore near-bottom flow is thicker and stronger at the onshore side of the shelf break in summer (Fig. 10b), where and when $v_{I}$ is weak. Presumably, flows in the bottom layer are the summation of $v_{\mathrm{I}}$ and the bottom Ekman flow associated with the alongshelf bottom stress. Because the along-shelf bottom velocity and the stress change relatively little over the seasons, the seasonal variation of the cross-shelf flow near the bottom layer mainly reflects the large seasonal variation of the interior onshore flow. Third, seasonal variations of $v_{I}$, weak in summer and strong in winter, are mostly consistent in model and observations, except in spring. The modeled springtime $v_{I}$ is very close to the summer values, but observations at the first two sites show otherwise. One possible reason for the discrepancy is the limited springtime coverage of the observations (April - May 1997), which may cause temporal aliasing toward early spring. This argument is supported by wind records in the study area in spring 1997, which show a sudden transition from the winter regime to the summer regime at the beginning of June. Another issue worth noting here is that, at the 125 -m site (Figs. 12e,f), modeled $v_{I}$ in fall and winter 
is about half of that observed and modeled mean surface Ekman depth in fall and winter is about $1 / 3$ of that observed. Similar discrepancies exist in the other two sites but to a lesser extent. Underestimation of the mean Ekman depth and transport is presumably caused by the use of steady wind in the model, which neglects strong nonlinear mixing events associated with storms in fall and winter. In response to the reduced surface offshore transport, the model reduces $v_{I}$ in fall and winter to conserve the volume on the shelf and thus decreases seasonal differences in $v_{I}$ (Fig. 12f). This implies that nonlinear processes, particularly those associated with strong mixing events, contribute to the mean circulation and the climatological model is unable to resolve the issue because of its intrinsic limitation. However, similarities between the modeled and observed seasonal variations of the cross-shelf flows demonstrate the model's capability of capturing the fundamental dynamics at the shelf break.

\section{Discussion}

In this section, we discuss several points that are related to the setup of the 2D model and implications of the model results. In particular, we justify the use of crossshelf varying along-shelf pressure gradient and crosssectional temperature and salinity nudging and examine further the modeled bottom boundary layer and shelfbreak upwelling.

\section{a. Treatment of the along-shelf pressure gradient}

The cross-shelf variation of the along-shelf sea level tilt (Fig. 8) imposed in the model brings a subtle mathematical issue to the 2D approach. Starting with the alongshelf gradient of (2),

$$
\begin{gathered}
\frac{\partial u}{\partial x} \frac{\partial v}{\partial x}+u \frac{\partial^{2} v}{\partial x^{2}}+\frac{\partial v}{\partial x} \frac{\partial v}{\partial y}+v \frac{\partial^{2} v}{\partial x \partial y}+f \frac{\partial u}{\partial x} \\
=-g \frac{\partial^{2} \eta}{\partial x \partial y}-\frac{g z}{\rho_{0}} \frac{\partial^{2} \rho}{\partial x \partial y}+\frac{1}{\rho_{0}} \frac{\partial^{2} \tau_{y}}{\partial x \partial z} .
\end{gathered}
$$

If strict along-shelf homogeneity $(\partial \cdot \partial x=0)$ is assumed for all variables except $\eta,(8)$ is left with only one term, $-g \partial^{2} \eta /(\partial x \partial y)$, and is therefore unbalanced. That is, it is impossible to impose the cross-shelf variation of the along-shelf sea level tilt in a truly 2D model.

However, the model used in this study is only quasi two dimensional, insofar as it has a 3-km along-shelf extension with periodic boundary conditions. This configuration allows the model to generate fluctuating along-shelf variation in the velocity fields of order $\partial v / \partial x \sim 10^{-7} \mathrm{~s}^{-1}$ and $\partial u / \partial x \sim 10^{-8} \mathrm{~s}^{-1}$. That gives $u \partial^{2} v / \partial x^{2}$ in (8) of order $10^{-11} \mathrm{~m}^{-1}$ to balance $-g \partial^{2} \eta /(\partial x \partial y)$. Meanwhile, the along-shelf advection term $u \partial v / \partial x$ is about three orders of magnitude smaller than the leading terms in (2) (pressure gradient, Coriolis, and stress) and therefore is still negligible in (2). A similar balance is achieved in the cross-shelf gradient of (1). The corresponding along-shelf gradient term in (3), $\partial u / \partial x$, is about two orders of magnitude smaller than the other two terms and (6) still holds. Therefore, the mathematical problem of having the cross-shelf variation of $\partial \eta / \partial x$ has a negligible effect on the momentum balances. On the other hand, the presence of the cross-shelf variation of $\partial \eta / \partial x$ has a huge effect on the shelfbreak circulation: it is essential for the modeled along-shelf velocity to match the observations (Fig. 4). Simulations with uniform $\partial \eta / \partial x$ (RPS-2b) give unrealistic high along-shelf velocity in the slope sea and reversed along-shelf velocity on the shallow part of the shelf (Figs. 4a, 11g-i).

\section{b. $2 D$ nudging}

For studying the climatological mean circulation, temperature, salinity and density can be assumed steady. In reality, a number of unsteady processes contribute to the mean fields, such as along-shelf advection, air-sea exchange, cross-shelf eddy flux, and cross-shelf flux induced by unsteady wind. Among them, along-shelf advection and cross-shelf eddy flux are inherently three dimensional and impossible for the 2D model to resolve; air-sea heat and salt exchange and cross-shelf flux induced by unsteady wind are neglected in the model for simplicity. To account for the effect of these missing processes, the temperature and salinity fields in the 2D model are nudged toward climatology.

As described in section 3a, the simulation without nudging (RPS-3) gives unsteady results and generates bottom-trapped, cross-shelf periodic, shoreward-moving recirculation cells, as a result of the symmetric instability. To evaluate the mean cross-shelf structure of the nonnudged case, we extended the domain in the along-shelf direction to $50 \mathrm{~km}$, slightly longer than the typical $40-\mathrm{km}$ along-shelf length scale of the shelfbreak front meander (Gawarkiewicz et al. 2004). The cross-shelf circulation pattern remains similar to RPS-3, except that the crossshelf scale of the bottom-trapped recirculation cells increases to $10 \mathrm{~km}$ from $4 \mathrm{~km}$. In addition, the shelfbreak front develops meanders. To compare with the baseline case (Figs. 9a-c), we computed a 100-day along-shelf average of the extended-domain simulation (Fig. 13). The along-shelf average of the extended-domain simulation gives a very similar circulation pattern to the nudged $2 \mathrm{D}$ simulation, with the exception of slightly raised isopycnals at the shelf break. The similarities suggest that the circulation pattern resolved by the nudged 2D model is robust compared to along-shelf averages of model fields with along-shelf variability. 


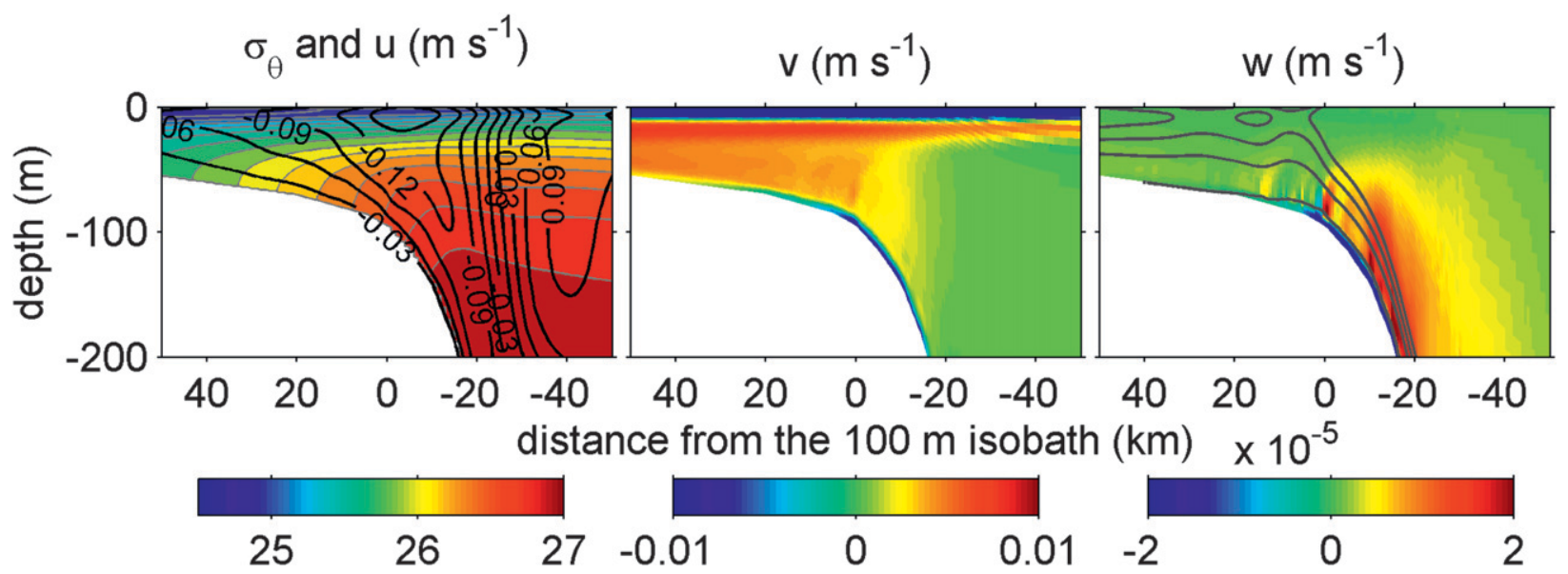

FIG. 13. (left) Density (color contour) and along-shelf velocity (black contour), (middle) cross-shelf velocity, and (right) vertical velocity given by the along-shelf-extended model. Lines in the right panel are some selected stream lines.

We now examine the physical meaning of the nudging terms in the baseline case with annual mean forcing to identify the processes that are missing in our 2D model but important for maintaining the cross-shelf density distribution (Fig. 14). Both the temperature and salinity nudging terms show a three-layer pattern around the shelf break with positive values in the surface and bottom layers and negative values in the interior, similar to that of the cross-shelf velocity (Fig. 9b). Nudging cools and freshens the interior, and it warms and adds salt to the surface and bottom layers. These tendencies counterbalance the effects of the cross-shelf circulation on the temperature and salinity fields (Figs. 3a,b, 7b).

The interior cooling and freshening appears consistent with along-shelf advection of temperature and salinity at the shelf break (Lentz 2010). Specifically, we used the magnitude of the nudging terms and the interior alongshelf velocity of $0.1 \mathrm{~m} \mathrm{~s}^{-1}$ (Fig. 9a) to estimate the equivalent along-shelf temperature and salinity gradients. The resulting estimates, $4 \times 10^{-6}{ }^{\circ} \mathrm{C} \mathrm{m}^{-1}$ and $2 \times 10^{-6}$ psu $\mathrm{m}^{-1}$, respectively, are similar to the observed alongshelf gradients at the shelf break in $\mathrm{MAB}\left(4 \times 10^{-6}{ }^{\circ} \mathrm{C} \mathrm{m}^{-1}\right.$ and $1-1.5 \times 10^{-6} \mathrm{psu} \mathrm{m}^{-1}$, respectively) (Lentz 2010). Thus, nudging in the interior in the 2D model can be interpreted as an analog of along-shelf advection of heat and salt in the 3D environment. Likewise, one can interpret the observed along-shelf temperature and salinity gradients in the interior as a result of the mean cross-shelf secondary circulation depicted in the 2D model.

In the surface layer, nudging heats the upper $15 \mathrm{~m}$ at a rate of $1.5 \times 10^{-6}{ }^{\circ} \mathrm{C} \mathrm{s}^{-1}$, which is equivalent to a surface heat flux of $100 \mathrm{~W} \mathrm{~m}^{-2}$, about half of the average

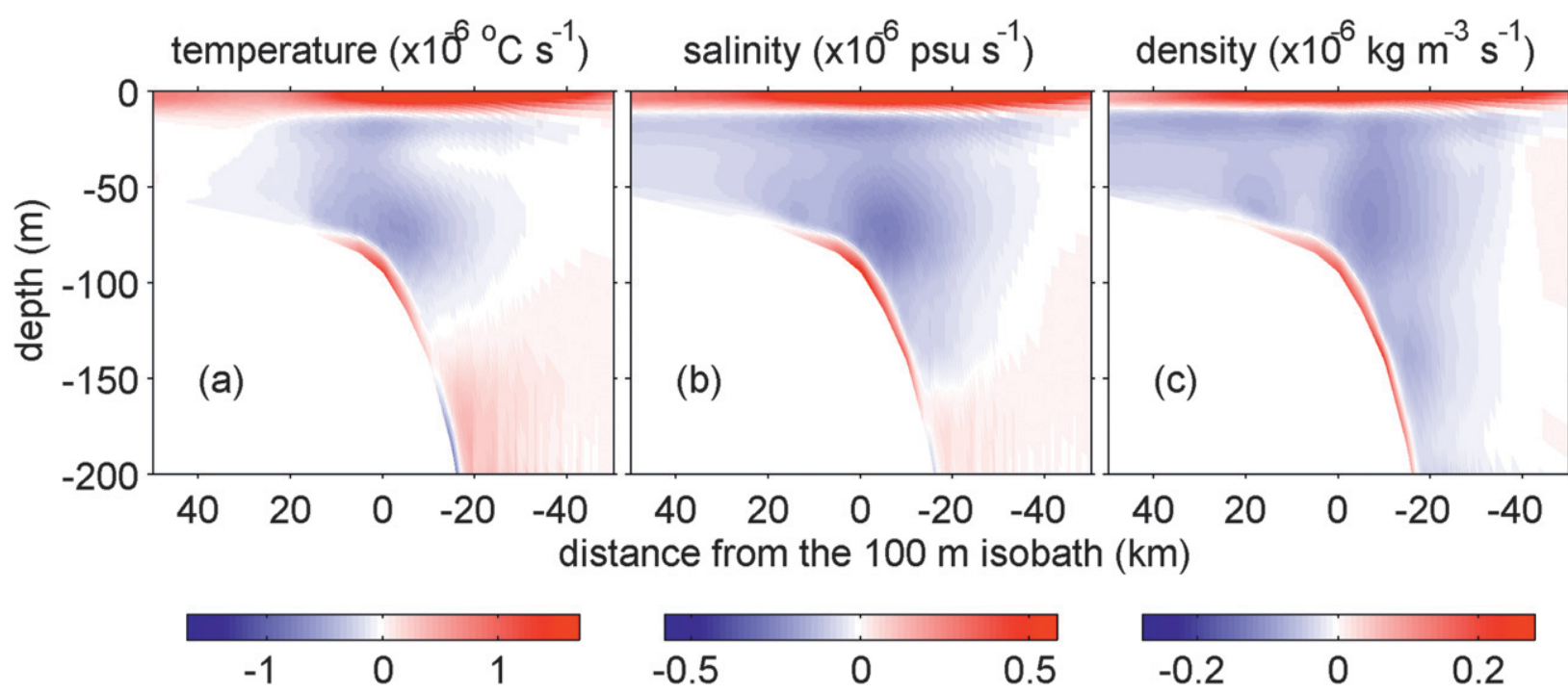

FIG. 14. Cross section of the nudging terms in tracer equations. A positive value means that nudging warms or adds salt to the water. 
incoming shortwave radiation in the area. Nudging adds salt to the upper $15 \mathrm{~m}$ at a rate of $0.6 \times 10^{-6} \mathrm{~s}^{-1}$, equivalent to a freshwater flux of $-2.6 \times 10^{-4} \mathrm{~kg} \mathrm{~m}^{-2} \mathrm{~s}^{-1}$, about 5 times the average evaporation rate in the area. Therefore, it is impossible for air-sea exchange to explain the surface nudging pattern. Either eddy-driven or unsteady wind-induced cross-shelf flux may play a major role, transporting heat and salt shoreward across the shelf break. Based on historical temperature and salinity observations and available meteorological products, Lentz (2010) examined the depth-integrated along-isobath heat and salt balances in the $\mathrm{MAB}$ and concluded that there must be a net shoreward heat and salt eddy flux at the shelf break. From repeated surveys across the shelfbreak front over a week period, Gawarkiewicz et al. (2004) observed onshore eddy fluxes of heat and salt in the upper $40 \mathrm{~m}$ near the shelfbreak front. However, the exact causes of the onshore eddy fluxes, whether due to eddy effects, unsteady winds, double diffusion, or some combination of processes, are still unknown.

In the bottom layer around the shelf break, warming and addition of salt by the nudging terms (Figs. 14a,b) is consistent with onshore heat and salt fluxes given the cross-shelf temperature and salinity gradients (Figs. 3b,c). These fluxes could represent the net effects of unsteady transport in the BBL. As will be described in section 4c, time-dependent processes around the shelf break can drive the BBL to depart from its mean state and fluctuate on shorter time scales. One possible consequence would be a suddenly detached BBL moving back and forth across the shelf break. The net heat and salt transport associated with the fluctuating BBL would be onshore, given the fact that water in the BBL is generally colder and fresher than the water offshore (Figs. 3b,c).

\section{c. Secondary circulation around the shelf break}

From our simulations, a conceptual model of the mean circulation at the shelf break emerges (Fig. 15). Sloping isopycnals cause a geostrophically balanced alongshore flow in the interior that is augmented by a cross-shelf tilt in sea level. Flows are directed offshore in the surface and bottom boundary layers, because of an eastward alongshelf component of the wind stress in the former and bottom Ekman layer dynamics in the latter. An alongshelf pressure gradient drives onshore flow in the interior, leading to upwelling at the shelf break as a result of continuity. We note that the illustrated upwelling is different from the synoptic upwelling on the offshore side of the shelfbreak front depicted by Csanady (1984). The latter is presumably caused by the divergence of the surface Ekman transport on the offshore side of the front, which, in turn, is driven by the cross-frontal variation of the alongshelf stress at the bottom of the Ekman layer (Cronin and Kesslier 2009). In essence, the frontal density gradient

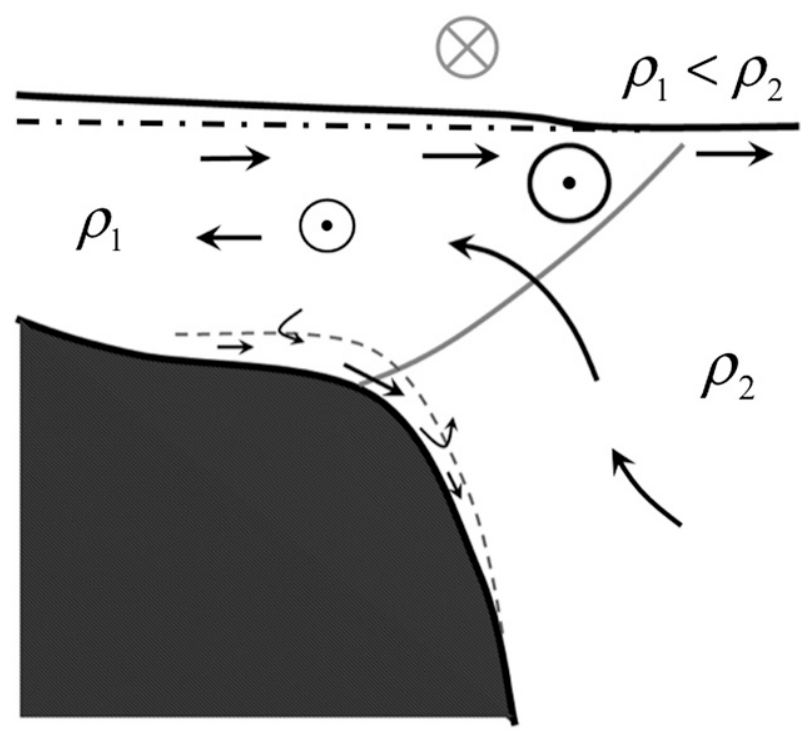

FIG. 15. Schematic of the mean circulation around the shelf break resolved by the 2D model. The gray cross cycle above the sea surface depicts the mean along-shelf component of the wind; the solid and dash-dotted black lines depict the tilted and undisturbed sea level, respectively; the solid gray line depicts an isopycnal; the dashed gray line outlines the top of the bottom layer; and dot circles and arrows depict along-shelf and cross-shelf flows, respectively. Symbols, arrows, and cross-shelf sea level tilt are not to scale.

drives the vertical shear of along-shelf velocity (i.e., alongshelf stress) through thermal-wind balance; the along-shelf stress at the bottom of the surface Ekman layer is eastward, partially balances the surface wind stress (dominantly eastward), and suppresses the Ekman transport at the front. This creates a divergence (convergence) of the surface Ekman transport and upwelling (downwelling) on the offshore (onshore) side of the front. However, the cross-shelf variation of the cross-shelf density gradient around the shelf break in the 2D climatology is rather small, about $10^{-5} \mathrm{~kg} \mathrm{~m}^{-4}$ in $50 \mathrm{~km}$. The associated along-shelf stress at the bottom of the Ekman layer varies by about $10^{-6} \mathrm{~Pa}$ in $50 \mathrm{~km}$ cross-shelf distance, which gives an upwelling velocity of $10^{-5} \mathrm{~m} \mathrm{day}^{-1}$ on the offshore side of the shelfbreak front, about four orders of magnitude smaller than the upwelling we obtained.

Vertical motion can also be generated by variation in wind stress that arises from computing the stress as the difference between wind and sea velocities (Dewar and Flierl 1987). Because the dominant along-shelf component of the wind around the New England shelf break is eastward, opposing the frontal jet, the effective wind stress is greater in the front than both offshore and inshore. This generates a divergence (convergence) of the surface Ekman transport and upwelling (downwelling) on the onshore (offshore) side of the front. The estimated 
upwelling velocity on the onshore side of the front in the 2D climatology is $2-4 \mathrm{~cm} \mathrm{day}^{-1}$, about one order of magnitude smaller than the modeled shelfbreak upwelling.

One feature of the mean state depicted in Fig. 15 is the gradual thinning of the offshore bottom flow offshore of the shelf break (also in Figs. 9, 10b). Flow in the bottom boundary layer transits offshore, and fluid at the top of the layer is entrained into the interior onshore flow. This picture of the flow in the bottom layer is different from the abrupt BBL detachment sometimes observed at the foot of the shelfbreak front (Houghton and Visbeck 1998). Sensitivity tests indicate that the offshore extension of the modeled bottom layer is controlled by the position of the offshore edge of the along-shelf pressure gradient. In all seasons, $\partial \eta / \partial x$ drops rapidly offshore of the $100-\mathrm{m}$ isobath (Fig. 8). However, the increase of the water depth counters that effect, and the along-shelf pressure gradient term at the shelf break in (4) remains larger than wind stress (Fig. 5, right). To balance that, the bottom water offshore of the 100-m isobath flows westward along shelf (out of the page in Fig. 9a). The associated Ekman dynamics drive the offshore component of the bottom flow. However, on shorter time scales, the offshore edge of $\partial \eta / \partial x$ may fluctuate across the shelf break because of unsteady $3 \mathrm{D}$ processes, such as tides, meandering of the shelfbreak front, and warm-core ring interactions. Consequently, the BBL might detach abruptly from the bottom and move across the shelf break. It is conceivable that seasonal and annual average of the transient states of the BBL will display a gradually detached BBL, as depicted in the 2D model.

Another feature of the modeled result is the deep source of the shelfbreak upwelling. Previous studies of the shelfbreak dynamics (Barth et al. 1998; Chapman and Lentz 1994; Houghton and Visbeck 1998) describe the upwelling as an along-isopycnal continuation of the detached BBL over the continental shelf reaching middepth. In contrast, the modeled upwelling starts from the offshore side of the shelf break and flows across isopycnals, and only a small portion of the upwelling stems from the continuation of the gradually detached bottom layer over the continental shelf (Figs. 9, 15). The source of the upwelled fluid in the $2 \mathrm{D}$ model is an inevitable consequence of the onshore interior flow in the slope sea that is distributed uniformly over the water column, except in the surface and bottom layers (similar to the velocity profiles in Fig. 12, right). At the shelf break, the onshore interior flow upwells, following the bathymetry. Here, we assume wind stress in the slope sea is balanced by the along-shelf pressure gradient associated with $\partial \eta / \partial x$ (tails of the nonzero tilt on the offshore side of the shelf break in Fig. 8). The barotropic along-shelf pressure gradient then drives the vertically uniform weak interior flow in the slope sea and generates the deep upwelling. Another possible force to balance the wind stress in the slope sea over seasonal to annual time scales is the baroclinic alongshelf pressure gradient associated with along-isobath density variation. Seasonal means of the three-dimensional climatology (Fleming and Wilkin 2010) in the slope sea exhibit some along-isobath density gradients in the upper $1000 \mathrm{~m}$ on $40-50-\mathrm{km}$ along-shelf scales, but the alongisobath variations cancels out on 200-300-km along-shelf scales. Given the relatively few observations available, the dominant balance of the temporally averaged and vertically integrated momentum in the slope sea is still uncertain. Nevertheless, the modeled upwelling could potentially bring nutrients up to the euphotic zone. Moreover, the deep slope water contains more nutrients than the bottom water on the shelf (G. G. Gawarkiewicz et al. 2010, unpublished manuscript).

Seasonal variation of the simulated shelfbreak upwelling (Fig. 9) raises an important question: how will the local biology react to the nutrient input from below? Presumably, strong upwelling in winter offers little stimulation to the local phytoplankton community, because wintertime phytoplankton growth is mostly light limited because of the deep surface mixed layer and reduced solar insolation (Schofield et al. 2008). Although upwelling in the spring and summer is weaker (about $0.3 \mathrm{~m}_{\text {day }}{ }^{-1}$ at 50-m depth), it is still favorable for phytoplankton growth in the euphotic zone. Continuous weak supply of nutrients from below might still be able to stimulate primary production and drive the observed biomass enhancement along the shelf break (Ryan et al. 1999b). Of course, synoptic processes and transient events may also play important roles. The response of the ecosystem around the shelf break to seasonal variation of the deep-sourced upwelling will be investigated in future studies.

Model results presented here focus on the New England shelf break. The mean circulation is different in other regions of the MAB (Hopkins 1982). As described in section 3 , wind is a major controlling factor of the circulation, and seasonal variation of the shelfbreak circulation is mainly driven by seasonal variation of the along-shelf component of the wind. Tests with different values of wind stress (not shown) reveal that the cross-shelf component of the wind has little influence on the mean circulation around the shelf break. Therefore, given a wind speed, the alignment between the wind direction and shelf orientation will affect the mean circulation. The New England shelf is east-west oriented, and the projection of the seasonal variation of wind stress onto the shelf orientation is large $\left(0.05 \mathrm{~N} \mathrm{~m}^{-2}\right.$ in winter and $0.002 \mathrm{~N} \mathrm{~m}^{-2}$ in summer). Farther to the south, the shelf is oriented southwest-northeast, whereas the wind direction is approximately the same (Lentz 2008a,b). Therefore, the effects of wind on the 
circulation on other parts of the MAB shelf might be different from those on the New England shelf, as depicted by Bush and Kupferman (1980) and Hopkins (1982). Applicability of the mean circulation presented in this paper to other parts of the MAB shelf break is unknown.

\section{Conclusions}

We have implemented a 2D circulation model around the New England shelf break. The model is forced at the surface with annual and seasonal mean wind stresses, and model temperature and salinity are nudged toward a 2D annual and seasonal climatology. A cross-shelf varying along-shelf pressure gradient body force is added to imitate the effect of along-shelf sea level tilt on the shelf. The modeled depth-averaged along-shelf velocity is tuned to fit observations by adjusting the along-shelf pressure gradient. Climatological cross-shelf and vertical circulation around the shelf break is obtained for annual and seasonal mean scenarios.

Model results demonstrate that circulation around the shelf break is mainly controlled by the balance between the wind stress and the barotropic along-shelf pressure gradient generated by the along-shelf sea level tilt. Wind stress drives the surface offshore Ekman flow; the imposed along-shelf pressure gradient drives onshore interior flow and accelerates the along-shelf flow over the whole water column, including the bottom flow. The enhanced along-shelf bottom stress helps the wind stress to balance the imposed along-shelf pressure gradient and also generates an offshore bottom Ekman flow; the strengthened along-shelf flow increases the Coriolis and then cross-shelf pressure gradient forces due to the geostrophic balance in the cross-shelf direction; the sea level is then raised farther in the onshore direction to generate the needed cross-shelf pressure gradient; the interior onshore flow, spanning between the base of the surface layer and the top of the bottom layer, is directed upward when it reaches the slope sea where water depth shallows suddenly and generates upwelling just offshore of the shelf break. Presumably, the upwelling brings nutrient-rich deep water to the euphotic zone and stimulates the local biological production, which is a potential mechanism for the observed springtime biomass enhancement along the shelf break.

Surface wind changes seasonally with the strongest westerly mean wind in winter and almost zero mean wind in summer, and, in comparison, the observed depth-averaged along-shelf velocity changes little. To account for this, the along-shelf sea level tilt has to vary over the seasons, with the largest along-shelf sea level tilt in winter and smallest in summer. Seasonal variation of the along-shelf pressure gradient drives seasonal variation of the interior onshore flow, which then causes seasonal variation of the upwelling at the shelf break and the bottom offshore flow. The modeled shelfbreak upwelling at $50 \mathrm{~m}$ varies from $2 \mathrm{~m} \mathrm{day}^{-1}$ in winter to $0.25 \mathrm{~m} \mathrm{day}^{-1}$ in summer. The springtime shelfbreak upwelling at $50 \mathrm{~m}$ is about $0.3 \mathrm{~m} \mathrm{day}^{-1}$. This is smaller than synoptic observations of the upwelling within the front (Houghton et al. 2006; Pickart 2000), suggesting that mesoscale features may be important factors driving frontal upwelling. The relative contribution of climatological upwelling versus synoptic upwelling to primary productivity within the front is an important topic for future study.

The modeled shelfbreak upwelling differs from the traditional view in that most of the upwelled water is from the upper continental slope instead of from the shelf in the form of a detached bottom boundary layer. In the model, the gradually detached bottom boundary layer contributes only a small portion of the upwelled water. We attribute the apparent discrepancy to the different time scales resolved by historical observations (daily) and the model (seasonal to annual). Lack of continuous observations over seasonal to annual time scales at the shelf break makes confirmation of the modeled upwelling impossible at this moment. However, construction of the Ocean Observatories Initiative Pioneer Array (Consortium for Ocean Leadership 2010) in the area in the near future will provide the necessary observations for direct testing of the modeled circulation.

This work provides the fundamental framework for future studies of the spatial and temporal variations of the shelfbreak processes in a fully three-dimensional environment. Simulations resolving the transient and inhomogeneous nature of the shelfbreak processes, together with systematic long-term observations in the area, are imperative for further quantification of the crossfrontal exchanges as well as elucidation of the mechanisms responsible for biomass enhancement at the front.

Acknowledgments. We thank Naomi Fleming for providing the 3D climatology and Steven Lentz, Ken Brink, and Keston Smith for discussions over the course of this study. WGZ was supported by the Woods Hole Oceanographic Institution postdoctoral scholarship program. GGG and DJM were supported by ONR Grant N-0001406-1-0739.

\section{REFERENCES}

Allen, J. S., and P. A. Newberger, 1998: On symmetric instabilities in ocean bottom boundary layers. J. Phys. Oceanogr., 28, $1131-1151$

Barth, J. A., D. Bogucki, S. D. Pierce, and P. M. Kosro, 1998: Secondary circulation associated with a shelfbreak front. Geophys. Res. Lett., 25, 2761-2764. 
Beardsley, R. C., and C. D. Winant, 1979: On the mean circulation in the Mid-Atlantic Bight. J. Phys. Oceanogr., 9, 612-619.

Benthuysen, J. A., 2010: Linear and nonlinear stratified spindown over sloping topography. Ph.D. thesis, Massachusetts Institute of Technology and Woods Hole Oceanographic Institution, $205 \mathrm{pp}$.

Biscaye, P. E., C. N. Flagg, and P. G. Falkowski, 1994: The shelf edge exchange processes experiment, SEEP-II: An introduction to hypotheses, results and conclusions. Deep-Sea Res. II, 41, 231-252, doi:10.1016/0967-0645(94)90022-1.

Bush, K., and S. L. Kupferman, 1980: Wind stress direction and the alongshore pressure gradient in the Middle Atlantic Bight. J. Phys. Oceanogr., 10, 469-471.

Chapman, D. C., 1985: Numerical treatment of cross-shelf open boundaries in a barotropic ocean model. J. Phys. Oceanogr., 15, 1060-1075.

— , and S. J. Lentz, 1994: Trapping of a coastal density front by the bottom boundary layer. J. Phys. Oceanogr., 24, 1464-1479.

Chen, K., and R. He, 2010: Numerical Investigation of the Middle Atlantic Bight shelfbreak frontal circulation using a highresolution ocean hindcast model.J. Phys. Oceanogr., 40, 949-964.

Cleveland, W. S., and S. J. Devlin, 1988: Locally weighted regression: An approach to regression analysis by local fitting. J. Amer. Stat. Assoc., 83, 596-610.

Consortium for Ocean Leadership, 2010: Ocean Observatories Initiative: Final network design. Consortium for Ocean Leadership Document 1101-00000, 170 pp.

Cronin, M. F., and W. S. Kesslier, 2009: Near-surface shear flow in the tropical Pacific cold tongue front. J. Phys. Oceanogr., 39, $1200-1215$.

Csanady, G. T., 1976: Mean circulation in shallow seas. J. Geophys. Res., 81, 5389-5399.

_ 1984: The influence of wind stress and river runoff on a shelfsea front. J. Phys. Oceanogr., 14, 1383-1392.

Dewar, W. K., and G. R. Flierl, 1987: Some effects of the wind on rings. J. Phys. Oceanogr., 17, 1653-1667.

Flagg, C., M. Dunn, D.-P. Wang, H. T. Rossby, and R. Benway, 2006: A study of the currents of the outer shelf and upper slope from a decade of shipboard ADCP observations in the Middle Atlantic Bight. J. Geophys. Res., 111, C06003, doi:10.1029/ 2005JC003116.

Flather, R. A., 1976: A tidal model of the northwest European continental shelf. Mem. Soc. Roy. Sci. Liege, 6, 141-164.

Fleming, N. E., and J. L. Wilkin, 2010: MOCHA: A 3-D climatology of the temperature and salinity of the Middle Atlantic Bight. Eos, Trans. Amer. Geophys. Union, 91 (Ocean Sci. Meet. Suppl.), Abstract PO35G-08.

Fratantoni, P. S., and R. S. Pickart, 2003: Variability of the shelf break jet in the Middle Atlantic Bight: Internally or externally forced? J. Geophys. Res., 108, 3166, doi:10.1029/2002JC001326.

Gawarkiewicz, G. G., and D. C. Chapman, 1992: The role of stratification in the formation and maintenance of shelf-break fronts. J. Phys. Oceanogr., 22, 753-772.

— , F. Bahr, R. C. Beardsley, and K. H. Brink, 2001: Interaction of a slope eddy with the shelfbreak front in the Middle Atlantic Bight. J. Phys. Oceanogr., 21, 2783-2796.

— , K. H. Brink, F. Bahr, R. C. Beardsley, M. Caruso, J. F. Lynch, and C.-S. Chiu, 2004: A large-amplitude meander of the shelfbreak front during summer south of New England: Observations from the Shelfbreak PRIMER experiment. J. Geophys. Res., 109, C03006, doi:10.1029/2002JC001468.

Hales, B., R. D. Vaillancourt, L. Prieto, J. Marra, R. Houghton, and D. Hebert, 2009: High-resolution surveys of the biogeochemistry of the New England shelfbreak front during summer, 2002. $J$. Mar. Syst., 78, 426-441.

Hopkins, T. S., 1982: On the sea level forcing of the Mid-Atlantic Bight. J. Geophys. Res., 87, 1997-2006.

Houghton, R. W., and J. Marra, 1983: Physical/biological structure and exchange across the thermohaline shelf/slope front in the New York Bight. J. Geophys. Res., 88, 4467-4481.

, and M. Visbeck, 1998: Upwelling and convergence in the Middle Atlantic Bight shelfbreak front. Geophys. Res. Lett., 25, 2765-2768.

_ C. N. Flagg, and L. J. Pietrafesa, 1994: Shelf-slope water frontal structure, motion and eddy heat flux in the southern Middle Atlantic Bight. Deep-Sea Res. II, 41, 273-306.

- D. Hebert, and M. Prater, 2006: Circulation and mixing at the New England shelfbreak front: Results of purposeful tracer experiments. Prog. Oceanogr., 70, 289-312, doi:10.1016/j.pocean. 2006.05.001.

_ R. R. Vaillancourt, J. Marra, D. Hebert, and B. Hales, 2009: Cross-shelf circulation and phytoplankton distribution at the summertime New England shelfbreak front. J. Mar. Syst., 78, 411-425, doi:10.1016/j.jmarsys.2008.11.023.

Lentz, S. J., 2008a: Seasonal variations in the circulation of the Middle Atlantic Bight continental shelf. J. Phys. Oceanogr., 38, 1486-1500.

_ 2008b: Observations and a model of the mean circulation over the Middle Atlantic Bight continental shelf. J. Phys. Oceanogr., 38, 1203-1221.

, 2010: The mean along-isobath heat and salt balances over the Middle Atlantic Bight continental shelf. J. Phys. Oceanogr., 40, 934-948.

Linder, C. A., and G. Gawarkiewicz, 1998: A climatology of the shelfbreak front in the Middle Atlantic Bight. J. Geophys. Res., 103, 18 405-18 423.

— — , and R. S. Pickart, 2004: Seasonal characteristics of bottom boundary layer detachment at the shelfbreak front in the Middle Atlantic Bight. J. Geophys. Res., 109, C03049, doi:10.1029/2003JC002032.

Lozier, M. S., M. S. Reed, and G. Gawarkiewicz, 2002: Instability of a shelfbreak front. J. Phys. Oceanogr., 32, 924-944.

Malone, T. C., T. S. Hopkins, P. G. Falkowski, and T. E. Whitledge, 1983: Production and transport of phytoplankton biomass over the continental shelf of the New York Bight. Cont. Shelf Res., 1, 305-337, doi:10.1016/0278-4343(83)90001-8.

Marra, J., R. W. Houghton, D. C. Boardman, and P. J. Neale, 1982: Variability in surface chlorophyll a at a shelf-break front. J. Mar. Res., 40, 575-591.

,-- , and C. Garside, 1990: Phytoplankton growth at the shelf-break front in the middle Atlantic Bight. J. Mar. Res., 48, 851-868.

Moody, J., and Coauthors, 1984: Atlas of tidal elevation and current observations on the northeast American continental shelf and slope. U.S. Geological Survey Bulletin 1611, $122 \mathrm{pp}$.

Mountain, D. G., 2003: Variability in the properties of Shelf Water in the Middle Atlantic Bight, 1977-1999. J. Geophys. Res., 108, 3014, doi:10.1029/2001JC001044.

Orlanski, I., 1976: A simple boundary condition for unbounded hyperbolic flows. J. Comput. Phys., 21, 251-269.

Pickart, R. S., 2000: Bottom boundary layer structure and detachment in the shelfbreak jet of the Middle Atlantic Bight. J. Phys. Oceanogr., 30, 2668-2686.

Ryan, J. P., J. A. Yoder, J. A. Barth, and P. C. Cornillon, 1999a: Chlorophyll enhancement and mixing associated with meanders 
of the shelf break front in the Mid-Atlantic Bight. J. Geophys. Res., 104, 23 479-23 493.

— - _ and P. C. Cornillon, 1999b: Enhanced chlorophyll at the shelfbreak of the Mid-Atlantic Bight and Georges Bank during the spring transition. Limnol. Oceanogr., 44, 1-11.

,-- , and D. W. Townsend, 2001: Influence of a Gulf Stream warm-core ring on water mass and chlorophyll distributions along the southern flank of Georges Bank. Deep-Sea Res. II, 48, 159-178.

Schofield, O., and Coauthors, 2008: The decadal view of the MidAtlantic Bight from the COOLroom: Is our coastal system changing? Oceanography, 21, 108-117.

Scott, J. T., and G. T. Csanady, 1976: Nearshore currents off Long Island. J. Geophys. Res., 81, 5401-5409.

Shchepetkin, A. F., and J. C. McWilliams, 2005: The Regional Oceanic Modeling System (ROMS): A split-explicit, free-surface, topography-following-coordinate oceanic model. Ocean Modell., 9, 347-404.

— , and — 2008: Computational kernel algorithms for finescale, multiprocess, long-term oceanic simulations. Handbook of Numerical Analysis. XIV: Computational Methods for the Ocean and the Atmosphere, P. G. Ciarlet, T. Temam, and J. Tribbia, Eds., Elsevier Science, 119-182.
Shearman, R. K., and S. J. Lentz, 2003: Dynamics of mean and subtidal flow on the New England shelf. J. Geophys. Res., 108, 3281, doi:10.1029/2002JC001417.

Stommel, H., and A. Leetmaa, 1972: Circulation on the continental shelf. Proc. Natl. Acad. Sci. USA, 69, 3380-3384.

Trowbridge, J. H., and S. J. Lentz, 1991: Asymmetric behavior of an oceanic boundary layer above a sloping bottom. J. Phys. Oceanogr., 21, 1171-1185.

Ullman, D. S., and D. L. Codiga, 2004: Seasonal variation of a coastal jet in the Long Island Sound outflow region based on HF radar and Doppler current observations. J. Geophys. Res., 109, C07S06, doi:10.1029/2002JC001660.

Umlauf, L., and H. Burchard, 2003: A generic length-scale equation for geophysical turbulence models. J. Mar. Res., 61, 235265.

Vaillancourt, R. D., J. Marra, L. Prieto, R. W. Houghton, B. Hales, and D. Hebert, 2005: Light absorption and scattering by particles and CDOM at the New England shelfbreak front. Geochem. Geophys. Geosyst., 6, Q11003, doi:10.1029/2005GC000999.

Walsh, J. J., P. E. Biscaye, and G. T. Csanady, 1988: The 1983-1984 shelf edge exchange processes (SEEP) - I Experiment: Hypotheses and highlights. Cont. Shelf Res., 8, 435-456, doi:10.1016/ 0278-4343(88)90063-5. 